\title{
COMPRESSION BEHAVIOR OF DOUBLER-PLATE REINFORCED SQUARE HOLLOW SECTION T-JOINTS
}

\author{
Hongfei Chang ${ }^{1,2 *}$, Junwu Xia ${ }^{1,2}$, Fengjie Zhang ${ }^{2,3}$ and Hong Chang ${ }^{2,3}$ \\ ${ }^{1}$ JiangSu Key Laboratory of Environmental Impact and Structural Safety in Engineering, \\ China University of Mining and Technology, Xuzhou, China \\ ${ }^{2}$ Key Laboratory of Deep Geotechnical and Underground Engineering, \\ China University of Mining and Technology, Xuzhou, China \\ ${ }^{3}$ School of Mechanics and Civil Engineering, China University of Mining and Technology, Xuzhou, China \\ *(Corresponding author: E-mail: honfee@126.com)
}

Received: 23 February 2013; Revised: 15 May 2013; Accepted: 39 June 2013

\begin{abstract}
The doubler-plate is widely used to improve the behavior of truss joints, and it has been proven to be effective in increasing the load carrying capacity of circle or square hollow section joints, yet the current design approach for doubler-plate reinforced joints is elementary. This study investigates the behavior of doubler-plate reinforced square hollow section (DPR-SHS) T-joints under brace compression, by experimental tests and finite element analysis (FEA). Details of the test arrangement were summarized, and the behaviors of failure modes, strain distribution and deformation characteristics of the specimens were analyzed. After confirming the accuracy of the finite element model with the test evidence, the reinforcement mechanism of doubler-plate was analyzed by parametric study. Both the experimental and FEA results shown the compression strength of the joint is significantly improved by welding a doubler-plate on the surface of the chord. The reinforcement efficiency of the doubler-plate increased with the increase of doubler-plate width and length, yet decreased with the increase of doubler-plate thickness and yielding strength. The thickness of doubler-plate influences the strength of the joint more than the width or length. Given a proper thickness, the reinforcement mechanism of the doubler-plate was yielding together with the chord flange. Finally, design formulas for DPR-SHS T-joints were proposed using yielding line method, which agree well with the experimental and FEA results. Yet the formula of Eurocode3-1-8 seems to oversimplify the design of DPR-SHS joint, which may lead to inaccurate estimation of the compression strength of the joint.
\end{abstract}

Keywords: Square hollow section, reinforced T-joints, doubler-plate, compression behavior, experiment, finite element, yielding line

\section{INTRODUCTION}

Tubular steel members are widely used in large span structures all around the world (Wardenier [1], Lesani [2]), for their structural efficiency as well as aesthetic quality. However, the hollow section members are known as weak in resisting the radial loading for thin wall (Packer [3], Shao [4]). On the other hand, the direct welded members often suffer high stress concentration at the connection zone (Nazari [5], Soh [6]), increasing the damage risk for the integral structure. As a result, joint reinforcement is always essential (Packer [3], Shao [4], Nazari [5], Soh [6], Lee [7]).

During the last decades, several reinforcing measures have been recommended to improve the behavior of tubular joints (Packer [3]). In general, these measures can be classified as internal reinforcement (Packer [3], Lee [7]) and external reinforcement (Hoon [8], Choo [9], Van [10], Fung [11], Choo [12], Feng [13], Korol [14], Korol [15], Soh [16]). The internal reinforcement such as stiffened ring, diaphragms, grout or horizontal stiffener, as well as chord wall local thickening (Yang [17]), has been proved efficient to increase the strength of the joint, while has little influence on the joint appearance (Packer [3], Lee [7]). However, the construction for internal reinforcement was not easy, for the tubular section is closed. In this regard, external reinforcement (Packer [3], CIDECT [21]) such as brace plate stiffeners, haunch stiffeners, truncated pyramid stiffeners, doubler or collar plate, FRP plate (Lesani [18]), through wall bolts (Jose [19]), were more appreciated for their reinforcement efficiency as well as fabrication convenience. Among 
these reinforcement measures, the use of doubler-plate is widespread. For a doubler-plate reinforced tubular joint (Figure 1), the doubler-plate is welded onto the chord surface by using filet weld, and then the brace is welded to the doubler-plate. This reinforcement is easy to fabricate and has little influence on the joint aesthetics, it can also improve the strength of the joint efficiently (Hoon [8], Choo [9], Van [10], Fung [11], Choo [12], Feng [13], Korol [14], Korol [15], Soh [16]).

Various references can be found related to doubler-plate reinforced joints (Hoon [8], Choo [9], Van [10], Fung [11], Choo [12], Feng [13], Korol [14], Korol [15], Soh [16]). The ultimate strength of doubler-plate reinforced circle hollow section (DPR-CHS) joints was investigated by experiment (Hoon [8], Choo [9]) or FE method (Van [10], Fung [11], Choo [12], Feng [13]), and the reinforcement mechanism as well as design recommendations for doubler-plate was put forward. However, note the load carrying mechanism of DPR-SHS joint is different from that of DPR-CHS ones (Korol [14]). Korol [14, 15] has proposed the flexural and compressive strength formulas of DPR-SHS joint using yield line theory, and verified the theory formulas by a set of laboratory test of DPR-SHS joints under brace bending [15]. Soh [16] has reported their test results on a DPR-SHS T-joint, and analyzed the ultimate strength of DPR-SHS joints using FE method. The influence of three geometric parameters such as the chord length $(\alpha)$, brace to chord diameter $(\beta)$ and chord diameter to thickness ratio $(\gamma)$ were investigated, and an equation was proposed by regression analysis. Soh [6] also compared the stress concentration factors (SCF) of DPR-SHS joints with unreinforced ones, and found that the doubler-plate can improve the fatigue performance of the joint.

Although there is no lack of experimental data for DPR-CHS joints (Hoon [8], Choo [9], Van [10], Fung [11], Choo [12]), little relevant experimental information is currently available for DPR-SHS joints subjected to brace compression load (Soh [16]). Because of the lack of test evidence, the current design approach for axially loaded DPR-SHS joints is elementary (EC3 [20], CIDECT [21]). To date, the configuration of doubler-plate for SHS joints proposed by Korol [14] is widely adopted by many standards or guidelines (CIDECT [21]) around the world. However, the applicability of these configurations should be re-examined. On the other hand, the design formula for DPR-SHS joints under compression is seldom available. The formula of Eurocode3-1-8 (EC3 [20]) seems oversimplify the design of DPR-SHS joint, which may misestimate the compression strength of the joint.

Thus, to investigate the compression behavior of DPR-SHS T-joints, a set of experimental tests were conducted. The design of specimens and arrangement of tests were described, and behaviors such as the failure modes, strain distribution and deformation characteristics of the specimens were discussed. Then, a finite element (FE) model was established and corroborated for further study. After confirming the accuracy of the FE model with the test evidence, the reinforcement mechanism of doubler-plate was analyzed by an extensive parametric study, and design formulas or recommendations for DPR-SHS T-joints under brace compression were proposed.

\section{EXPERIMENTAL INVESTIGATIONS}

\subsection{Details of Specimens}

For a DPR joint, the strength of the joint is improved by welding a doubler-plate onto the surface of the chord. This reinforcement is applicable to tubular joints governs by chord surface yielding (EC3 [20]). Figure 1 shows the configuration of a square tubular T-joint with doubler-plate reinforcement. In addition, some geometric parameters are also indicated in the same figure, and the quantities of specific parameters are listed in Table 1. Coupon tests were conducted before the 
experimental test, and the measured yield stresses of the steel materials are also tabulated in Table 1. For convenience, any quantity with a subscript " 0 ", " 1 " or " 2 " denotes a geometric or mechanical parameter of the chord, the brace and the doubler-plate respectively.

A total of two T-joints without any reinforcement and two T-joints reinforced with doubler-plate were designed for experimental test. In the design of the four specimens, the square tubular joints had different values of one critical geometric parameter, namely $\beta$. For comparison purpose, the unreinforced T-joints and the reinforced ones had the same geometric dimensions for the chord and the brace. For brevity, the doubler-plate was designed to have same thickness, while the length and the width of the plate were different. Therefore, the four specimens were classified as two groups as tabulated in Table 1. Each group includes one unreinforced specimen (namely: URT) and one corresponding specimen with doubler-plate reinforcement (namely: DPT).
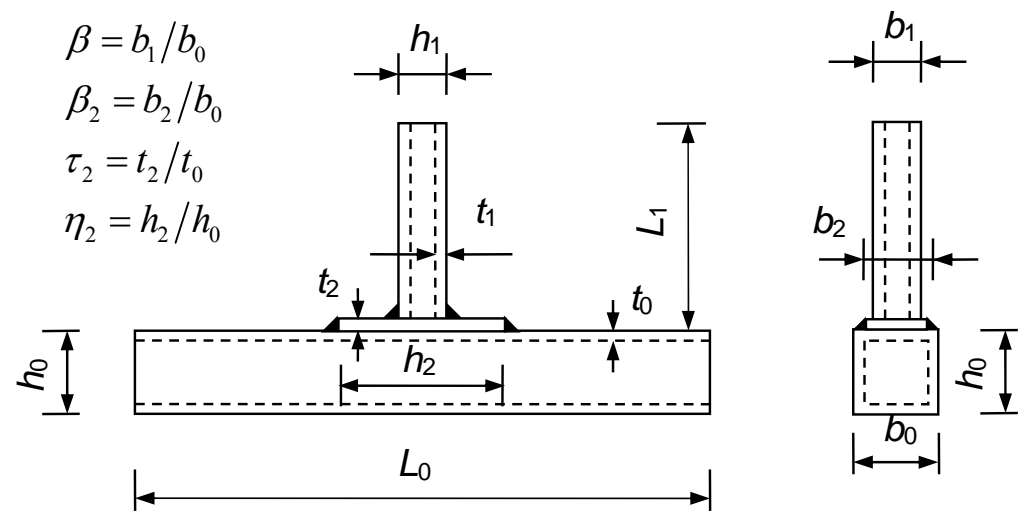

Figure 1. Details of Doubler-plate Reinforced Square Tubular T-joint

Table 1. Geometry and Material Properties of the Specimens

\begin{tabular}{c|c|c|c|c|c|c|c|c|c|c|c|c|c|c}
\hline \multirow{2}{*}{ No } & \multicolumn{4}{|c|}{ Chord } & \multicolumn{4}{c|}{ Brace } & \multicolumn{4}{c}{ Doubler-plate } \\
\cline { 2 - 16 } & $b_{0}$ & $h_{0}$ & $t_{0}$ & $L_{0}$ & $f_{\mathrm{y} 0}$ & $b_{1}$ & $h_{1}$ & $t_{1}$ & $L_{1}$ & $f_{\mathrm{y} 1}$ & $b_{2}$ & $h_{2}$ & $t_{2}$ & $f_{\mathrm{y} 2}$ \\
\hline URT-40 & 100 & 100 & 5 & 650 & 356 & 40 & 40 & 4 & 300 & 372 & \multicolumn{4}{|c}{-} \\
\hline DPT-40 & 100 & 100 & 5 & 650 & 356 & 40 & 40 & 4 & 300 & 372 & 70 & 75 & 7 & 285 \\
\hline URT--80 & 100 & 100 & 5 & 650 & 356 & 80 & 80 & 4 & 300 & 265 & \multicolumn{4}{|c}{-} \\
\hline DPT-80 & 100 & 100 & 5 & 650 & 356 & 80 & 80 & 4 & 300 & 265 & 88 & 160 & 7 & 285 \\
\hline
\end{tabular}

Note: All geometry parameters are in $m m, f_{\mathrm{y} 0}, f_{\mathrm{y} 1}$ and $f_{\mathrm{y} 2}$ is the yielding strength of the chord, the brace and the doubler-plate steel in $\mathrm{N} \cdot \mathrm{mm}^{-2}$ respectively.

\section{$2.2 \quad$ Test Arrangement}

As shown in Figure 2, the specimens were fixed at both ends of the chord (Wu [22], Chang [23]), and the monotonic loading was applied at the brace end by an electro-hydraulic servo actuator with a maximum capacity of $1000 \mathrm{kN}$. To control the large deformation may occur in the stage of plastic flow, a vertical displacement at the brace end was used in the loading program. Once the displacement was applied at the brace end, the required axial loading can be measured automatically by the machine.

For each specimen, the instrumentation included transducers to measure the displacements and strain distribution at selected points. Figure 2 (a) shows the general arrangement of the displacement transducers, with six of these (namely DT1, DT2, DT3 and DT6, DT7, DT8) symmetrically arranged on the surface of the chord measuring the displacements of the chord, and 
one transducer (namely: DT4) measuring the displacement of the brace end. In addition, another transducer (namely: DT5) was placed under the chord at the center of the T-joint, monitoring the vertical displacement of the chord bottom surface. Figure 2 (b) shows the general arrangement of the strain gauges on the surface of the chord. The strain gauges were located $15 \mathrm{~mm}$ away from the brace-to-chord weld toe for unreinforced joints, and $15 \mathrm{~mm}$ away from the plate-to-chord weld toe for DPR-SHS joints. Three groups of strain gauges (namely SG1, SG2 and SG3) were arranged near the brace-to-chord intersection for each specimen. For each group, there were three strain gauges, located on the angle of 0,45 and 90 degree respectively.

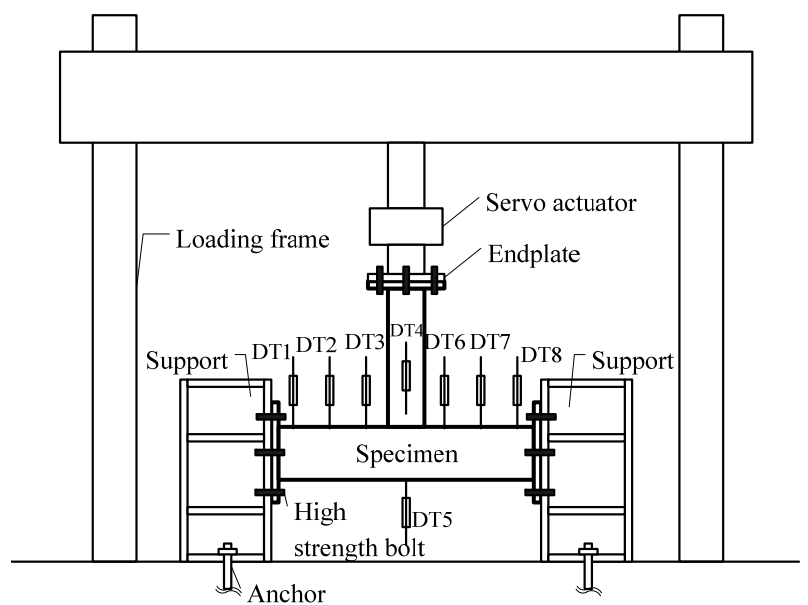

(a)

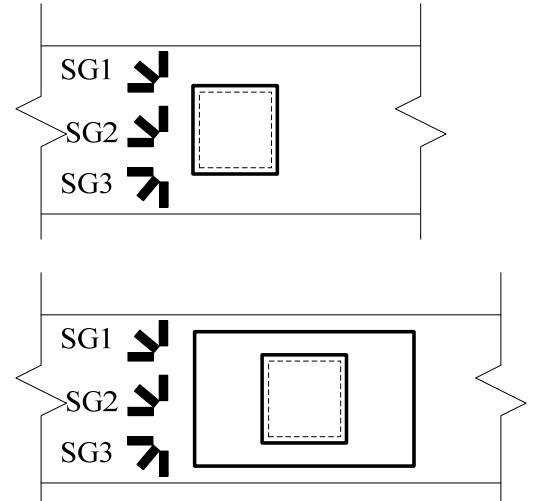

(b)

Figure 2. Arrangement of Test Specimen and Instruments:

(a) Front View; (b) Strain Gauges Layout

\subsection{Observations from Experimental Test}

For unreinforced square tubular T-joints, two kinds of failure modes namely chord surface yielding or chord web buckling are frequently occurred (EC3 [20], CIDECT [21]). As to the unreinforced specimen URT-40, indentation of the chord surface appeared under a small brace compression. With the growth of brace compression load, the indentation increased and the up fillet of the chord yielded. Finally, the test terminated after the indentation of the chord surface was about $15 \mathrm{~mm}$. Figure 3 (a) shows the chord surface yielding failure of the unreinforced specimen URT-40. The brace-to-chord width ratio of specimen URT- 80 was 0.8 , little indentation of the chord surface was observed. However, the chord web buckled suddenly when the brace load reached at $200 \mathrm{kN}$, and the strength of the joint decreased slightly. The failure mode of specimen URT-80 was chord web buckling and surface yielding, as shown in Figure 3 (b).

For reinforced specimen DPT-40, indentation of the chord surface was invisible until the load reached about $140 \mathrm{kN}$. With the growth of brace compression load, the indentation increased and the doubler-plate bent. The test terminated after the compression of the brace reached at $200 \mathrm{kN}$, which leading to overall bending of the chord. Figure 3 (c) shows the yielding of chord surface and doubler-plate for DPT-40. For specimen DPT-80, no indentation of the chord surface appeared even before $300 \mathrm{kN}$. As the load reached about $380 \mathrm{kN}$, the brace buckled suddenly and the compression strength of the joint decreased rapidly. The failure of specimen DPT- 80 is brace buckling as shown in Figure 3 (d). 


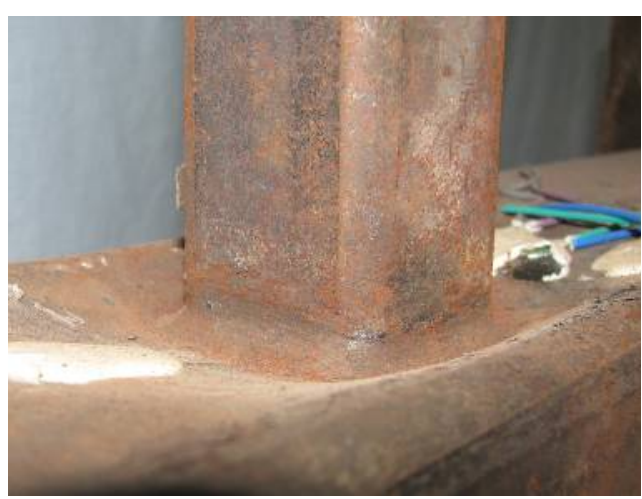

(a) URT-40

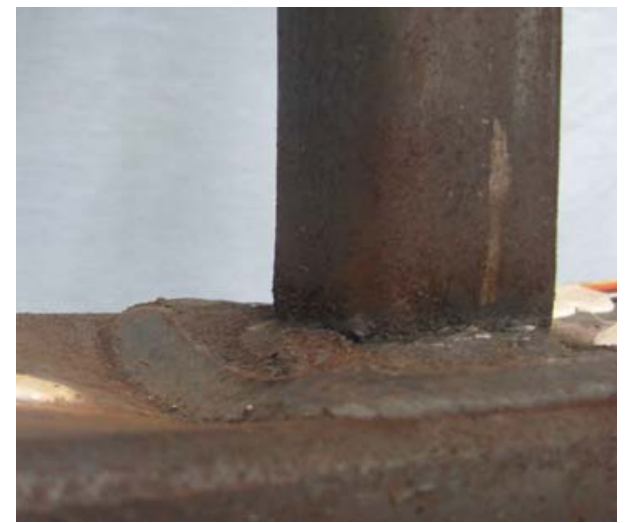

(c) DPT-40

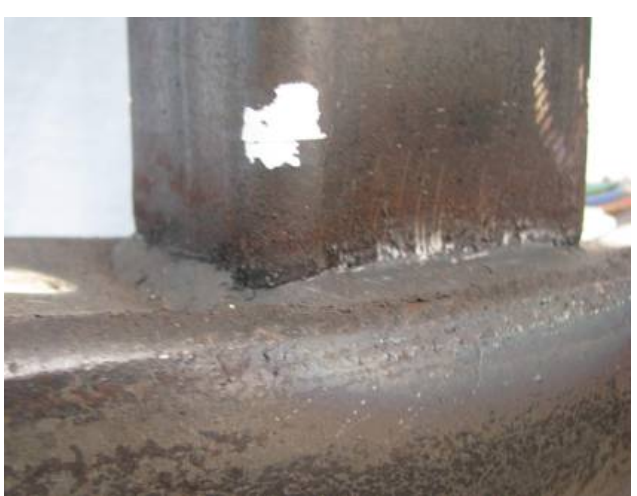

(b) URT-80

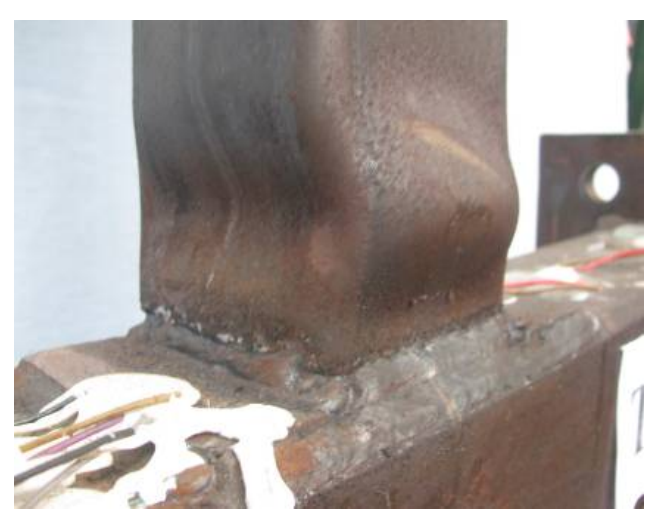

(d) DPT-80

Figure 3. Failure Modes of the Joints

\subsection{Strain Distribution of the Chord}

Figure 4 presents the load-strain curve for each of the four tested specimens. For unreinforced specimen URT-40, strain of the chord surface increased obviously as the brace compression exceed about $60 \mathrm{kN}$, demonstrating a local yielding of the joint occurred. The load-strain curves of specimen URT-80 almost remained a linear growth even before the failure of the joint. The strength of the joint kept unchanged as the load reached about $200 \mathrm{kN}$, for the buckling of the chord web occurred. The buckling of the web also leading to the bending of the flange, and the strain of the chord surface increased rapidly.

For the joint with doubler-plate reinforcement, the strain distribution law of the chord surface was almost the same to the unreinforced ones. For specimen DPT-40, strain of the chord surface increased slowly before $160 \mathrm{kN}$, then increased rapidly after $160 \mathrm{kN}$. The strain of specimen DPT-80 was small before the compression load of the brace reached about $350 \mathrm{kN}$. Although the strain of the chord surface increased after the load of $350 \mathrm{kN}$, a sudden drop of the load appeared because the buckling of the brace. 


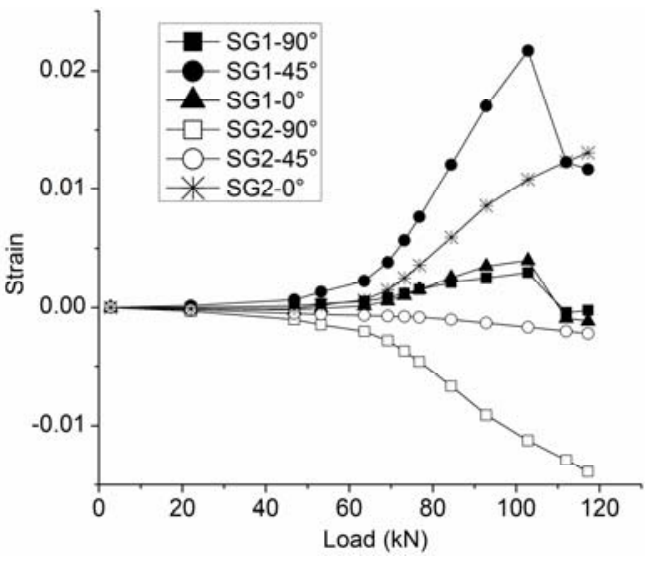

(a) URT-40

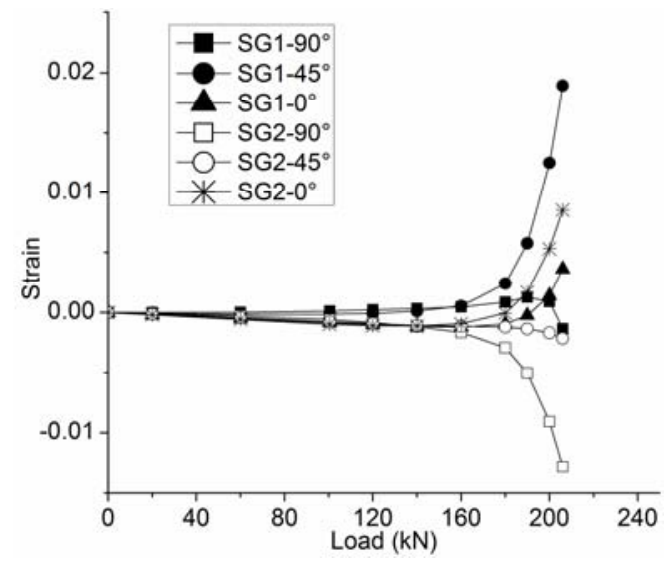

(c) DPT-40

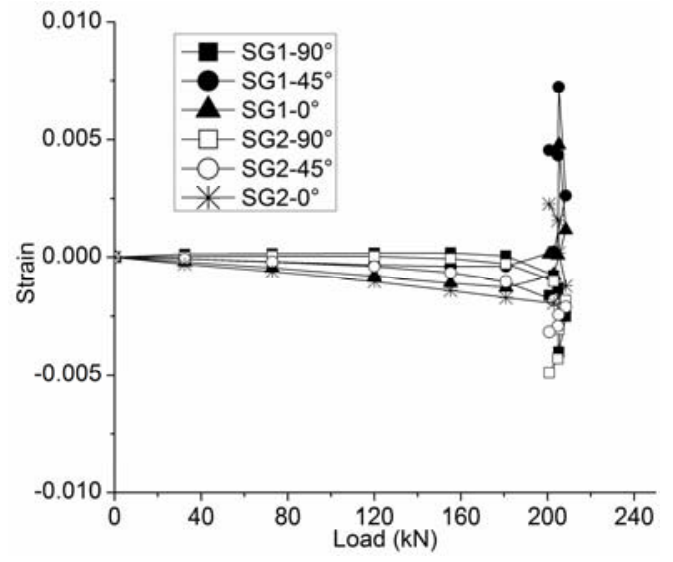

(b) URT-80

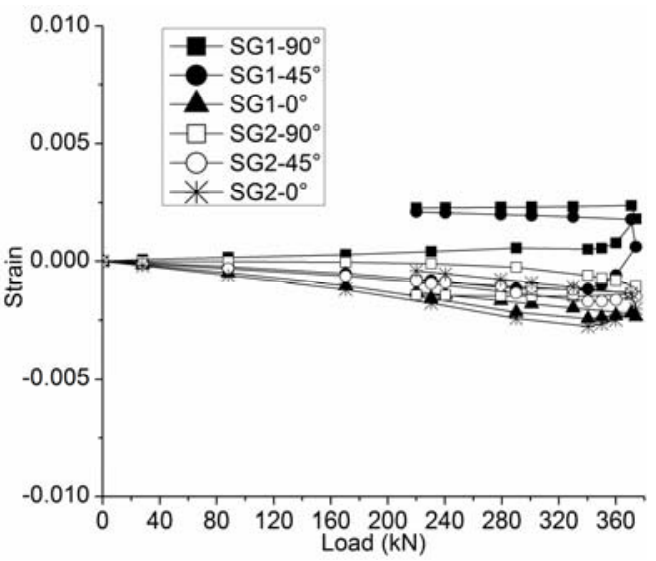

(d) DPT-80

Figure 4. Load-strain Curves of Chord Flange

\subsection{Deformation of the Chord}

In this section, the deformation data of the chord obtained from the experiments are presented and evaluated. First, the displacement readings under a certain brace compression of all the eight transducers are shown in Figure 5. The displacement of DT1 3 and DT5 8 displayed the overall bending of the chord, and DT4 shown the deformation of the brace-chord intersection. As a result, the local deformation of the brace-chord intersection can be obtained from the difference between DT4 and DT5. It can be seen the overall bending of the chord occurred before the load of 60, 200, 160 and $378 \mathrm{kN}$ for specimen URT-40, URT-80, DPT-40 and DPT-80 respectively, as the difference between DT4 and DT5 is small. This agrees well with the findings of the chord surface strain distribution. 


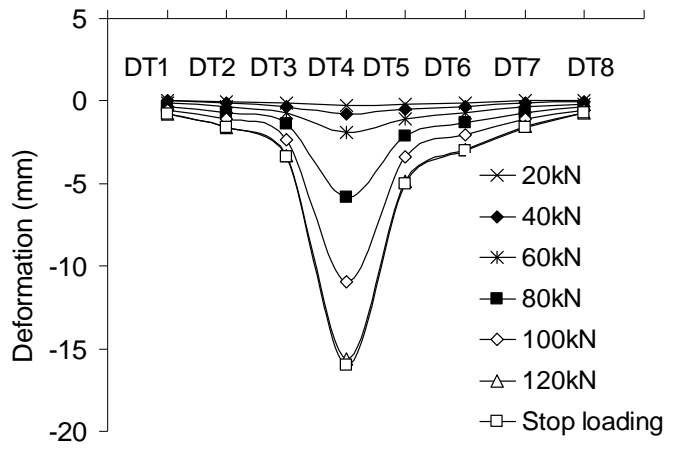

(a) URT-40

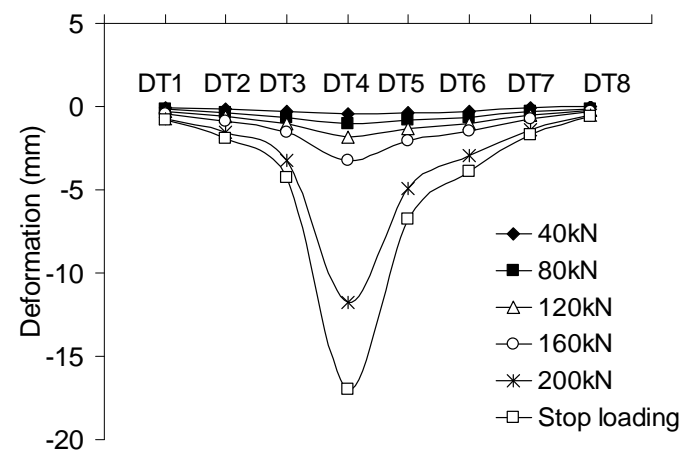

(c) DPT-40

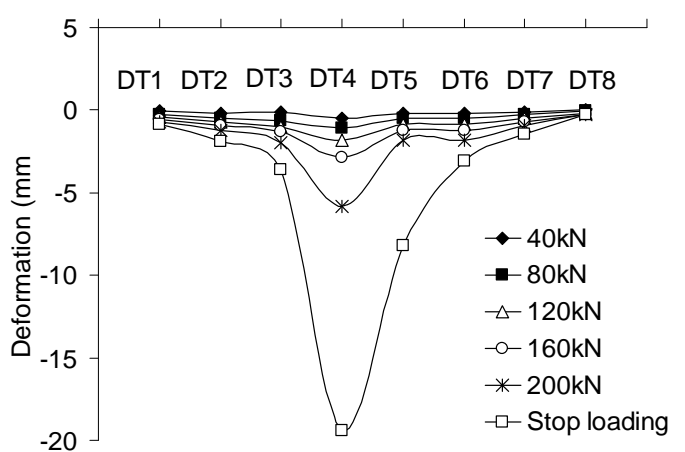

(b) URT-80

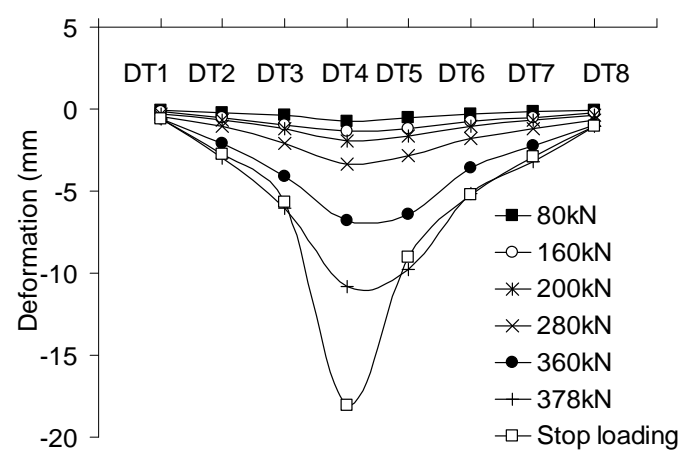

(d) DPT-80

Figure 5. Deformation Details of the Chord

\subsection{Strength of the Joints}

For the strength evaluation of a tubular joint, the load-deformation curve is widely used (Lu [24], Zhao [25]). Lu [24] has proposed a general deformation limit based on the load-deformation curve, to cover all types of welded hot-rolled section tubular joints. Then Zhao [25] confirmed the applicability of the proposed deformation limit for welded T-joints in cold-formed rectangle hollow sections. Zhao [25] investigated the test results of web buckling failure and chord flange failure, and suggested the deformation limit for cold-formed rectangle hollow section T-joints should be $3 \% b_{0}$ for $0.6 \leq \beta \leq 0.8$ or $2 \gamma \leq 15$ and $1 \% b_{0}$ for $0.3 \leq \beta<0.6$ and $2 \gamma>15$.

The load-deformation curves of the tested specimen are shown in Figure 6. For DPR-SHS T-joints, the load-deformation curves were above the curves for the unreinforced ones. The deformation refers to the displacement of the chord cross section at the center of the T-joint, which was calculated by subtracting the average value of the two transducer readings at the chord ends (namely: DT1 and DT8), from the transducer reading near the chord-brace intersection (namely: DT4).

By using Zhao's [25] method, the compression strength of each specimen was determined and listed in Table 2. It is found from Table 2 the doubler-plate reinforced joint is "stronger" than the unreinforced joint and hence exhibits a larger ultimate strength. For specimen DPT-40, the strength improvement is up to $136 \%$ compared to the unreinforced one. However, the increase of DPT- 80 is only $56 \%$ because of the over-reinforcement of the joint, which leading to the buckling of the brace occurred unexpectedly. Table 2 also lists the ultimate strength determined by EC3 [20], which agree well with the test results with a mean ratio of 0.875 and a coefficient of variation $(\mathrm{COV})$ of 
0.009. However, the EC3 [20] underestimates the strength of DPT-40, yet overestimates the strength of DPT-80.

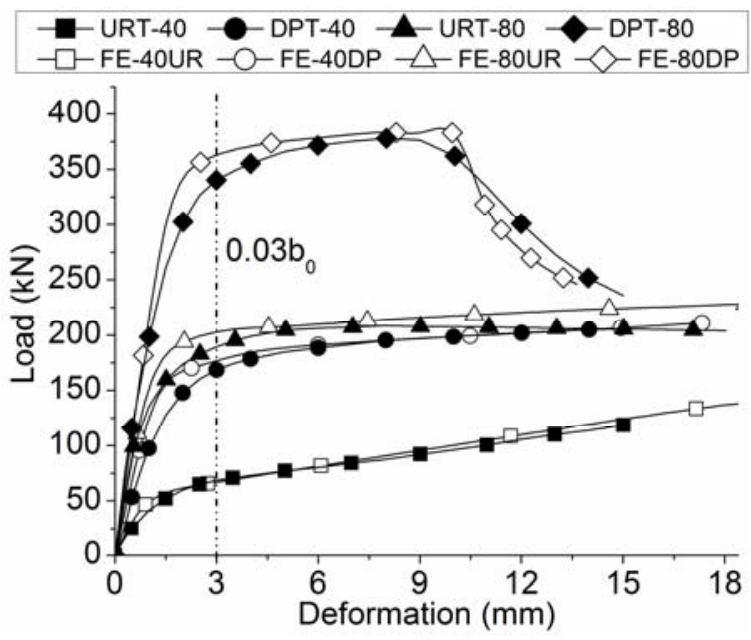

Figure 6. Load-deformation Curves of Specimens

Table 2. Compression Strength of the Specimens

\begin{tabular}{c|c|c|c|c|c|c|c|c|c}
\hline Specimens & $\begin{array}{c}\text { Failure } \\
\text { mode }\end{array}$ & $\begin{array}{c}\mathrm{P}_{1 \%} \\
/(\mathrm{kN})\end{array}$ & $\begin{array}{c}\mathrm{P}_{3 \%} \\
/(\mathrm{kN})\end{array}$ & $\begin{array}{c}\mathrm{P}_{3 \%} \\
/ \mathrm{P}_{1 \%}\end{array}$ & $\begin{array}{c}\mathrm{P}_{\max } \\
/(\mathrm{kN})\end{array}$ & $\begin{array}{c}\mathrm{P}_{\mathrm{ult}} \\
/(\mathrm{kN})\end{array}$ & $\begin{array}{c}\mathrm{P}_{\mathrm{DPT}} / \\
\mathrm{P}_{\mathrm{URT}}\end{array}$ & $\begin{array}{c}\mathrm{P}_{\mathrm{EC} 3} \\
/(\mathrm{kN})\end{array}$ & $\begin{array}{c}\mathrm{P}_{\mathrm{EC} 3} \\
/ \mathrm{P}_{\text {ult }}\end{array}$ \\
\hline URT-40 & FY & 41.6 & 68.8 & 1.65 & 119.2 & 62.4 & 1.0 & 57.8 & 0.93 \\
\hline DPT-40 & $\begin{array}{c}\text { FY+DP } \\
\mathrm{Y}\end{array}$ & 98.4 & 168.4 & 1.71 & 207.2 & $\begin{array}{c}147 . \\
6\end{array}$ & 2.36 & 113.3 & 0.77 \\
\hline URT-80 & FY+WB & 135.2 & 189 & 1.4 & 208.4 & 189 & 1.0 & 150.8 & 0.80 \\
\hline DPT-80 & BB & 197 & 340.4 & 1.73 & 378 & $\begin{array}{c}295 . \\
5\end{array}$ & 1.56 & 295.6 & 1.0 \\
\hline MEAN & & & & & & & & & 0.875 \\
\hline COV & & & & & & & & & 0.009 \\
\hline
\end{tabular}

Note: (1) FY: chord flange yielding, DPY: doubler-plate yielding, WB: chord web buckling, BB: brace buckling

(2) $\mathrm{P}_{1 \%}$ and $\mathrm{P}_{3 \%}=$ load when the brace deformation was $1 \% \mathrm{~b}_{0}$ and $3 \% \mathrm{~b}_{0} ; \mathrm{P}_{\max }=$ maximum load of the test; $\mathrm{P}_{\mathrm{ult}}=$ ultimate strength of the joint; $\mathrm{P}_{\mathrm{EC} 3}=$ ultimate strength determined by EC3 [20].

\section{PARAMETRIC STUDY}

\subsection{Finite Element Strategy}

Because of the high costs of laboratory tests, the FE packages were widely used to offer an attractive and cheaper alternative to generate reliable additional data, provided the accuracy of the FE model was first verified with the test evidence. There are many publications related to the numerical simulation of unreinforced or doubler-plate reinforced T-joints (Van [10], Fung [11], Choo [12], Feng [13], Soh [16]). The behaviors of DPR-CHS T-joints (Van [10], Fung [11]); $\mathrm{X}$-joints (Choo [12]); Y-joints (Feng [13]) as well as DPR-SHS T-joints (Soh [16]) were investigated. 
In the current study, a numerical model was developed to simulate the 4 experimental specimens. Because the doubler-plate configurations require the definition of contact between the various components, the joints were modeled using 20-noded solid elements (Van [10], Soh [16]). The contact between the doubler-plate and the chord surface was modeled using surface-to-surface contact element. In the FE model, the material property was the same as the test, and a bilinear stress-strain relationship was assumed. The elastic modulus was $200 \mathrm{GPa}$, and the hardening modulus was 1/100th of the elastic modulus (Shao [4]). The chord was fixed on the ends, and a displacement controlled compression loading was applied on the end of the brace until the failure of the joint. For each FE model, the element size varied in such a way that smaller elements were used where the stress gradient was more critical. Therefore the mesh density decreases from the vicinity of the intersection to the end of the brace or chord. Preliminary FE analyzes showed that such mesh density was able to produce results with good accuracy. A linear search algorithm was adopted to solve the problem, and the auto time stepping was activated to decrease the iteration. To decrease the computational time, a quarter of the T-joint was modeled. The meshing detail of the model is pictured in Figure 7.

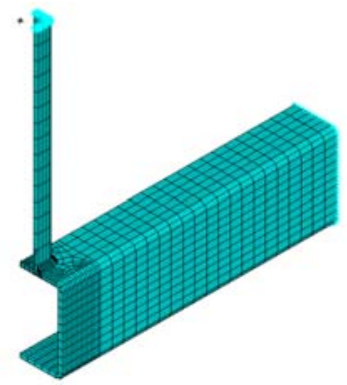

(a) FE model,

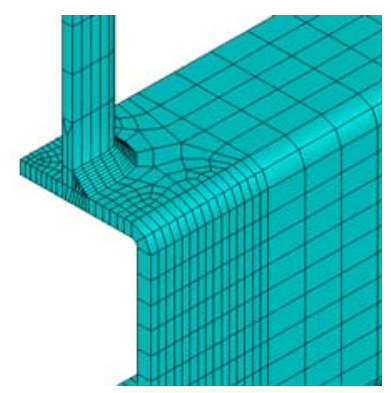

(b) unreinforced joint,

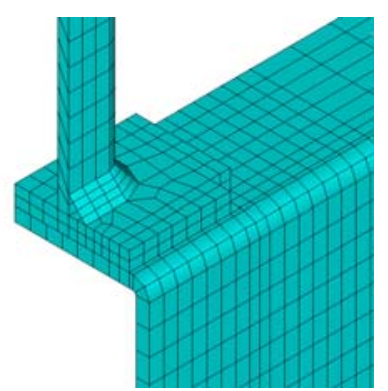

(c) doubler-plate reinforced joint

Figure 7. Finite Element Models of the Test Specimens

\subsection{Comparison between Experimental and Numerical Results}

Because the plastic cumulative damage and crack development of the steel or weld was ignored in the FE model, the maximum displacement of the brace end was determined as $20 \mathrm{~mm}$. Nevertheless, the good agreement between the experiments and numerical results of failure modes can be observed in Figure 8, where the specimen FE40-UR and FE40-DP failure by yielding of chord surface or doubler-plate; FE80-UR by buckling of chord web and FE80-DP by buckling of the brace.

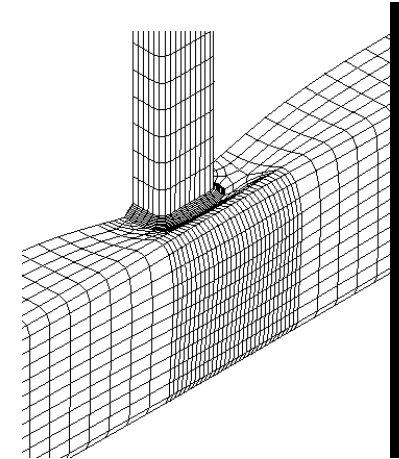

(a) FE40-UR;

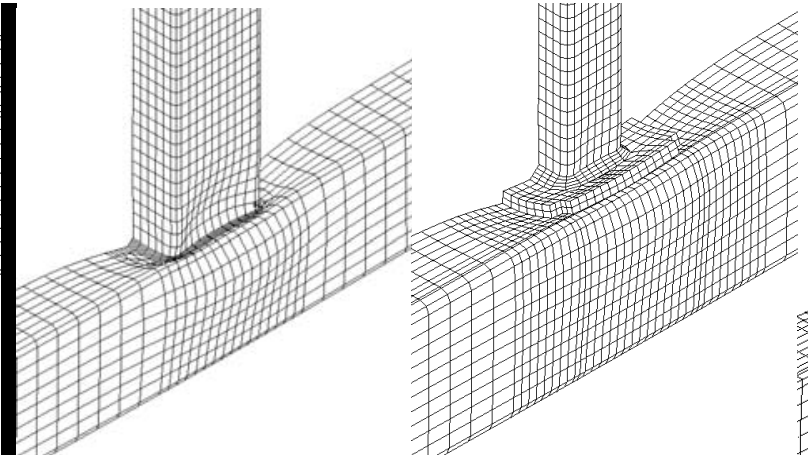

(c) FE40-DP;

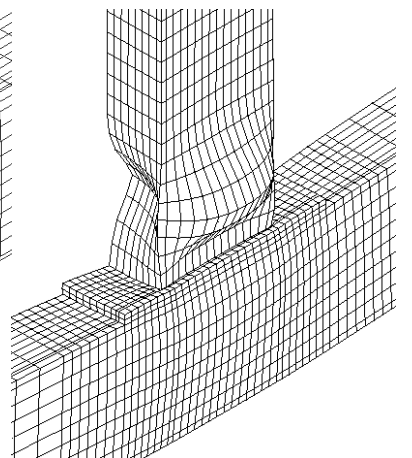

(d) FE80-DP

Figure 8. FEA Failure Modes 
The numerically determined load-deformation curves are presented in Figure 6, together with the solid lines of experimental curves. The FEA determined ultimate strength of the joint is summarized in Table 3. As can be observed from Figure 8 and Table 3, the numerical and experimental results matched well, the average ultimate strength of FEA was $10 \%$ above that of the test with a COV of 0.003 . This discrepancy was not surprising since the current FE models ignored the geometry negative deviation of the chord or brace, as well as the thermal effect of welding. Anyway, the accuracy of the FE model was satisfactory for the strength evaluation of the unreinforced or DPR-SHS T-joints under brace compression.

Table 3. Ultimate Strength of the FE Simulation

\begin{tabular}{c|c|c|c|c|c|c|c}
\hline Specimen & $\begin{array}{c}\text { Failure } \\
\text { mode }\end{array}$ & $\begin{array}{c}\mathrm{P}_{1 \%} \\
/(\mathrm{kN})\end{array}$ & $\begin{array}{c}\mathrm{P}_{3 \%} \\
/(\mathrm{kN})\end{array}$ & $\begin{array}{c}\mathrm{P}_{3 \%} \\
/ \mathrm{P}_{1 \%}\end{array}$ & $\begin{array}{c}\mathrm{P}_{\mathrm{FE}} \\
/(\mathrm{kN})\end{array}$ & $\begin{array}{c}\mathrm{P}_{\text {ult }} \\
/(\mathrm{kN})\end{array}$ & $\begin{array}{c}\mathrm{P}_{\mathrm{FE}} \\
/ \mathrm{P}_{\text {ult }}\end{array}$ \\
\hline FE40-UR & FY & 48.3 & 66.8 & 1.38 & 66.8 & 62.4 & 1.07 \\
\hline FE40-DP & FY+DPY & 120.4 & 176.3 & 1.46 & 176.3 & 147.6 & 1.19 \\
\hline FE80-UR & FY+WB & 146.3 & 201.8 & 1.38 & 201.8 & 189 & 1.07 \\
\hline FE80-DP & BB & 210.4 & 362.1 & 1.72 & 315.6 & 295.5 & 1.07 \\
\hline MEAN & & & & & & & 1.1 \\
\hline COV & & & & & & & 0.003 \\
\hline
\end{tabular}

Note: (1) FY: chord flange yielding; DPY: doubler-plate yielding; WB: chord web buckling; BB: brace buckling;

(2) $\mathrm{P}_{1 \%}$ and $\mathrm{P}_{3 \%}=$ load when the brace deformation was $1 \% b_{0}$ and $3 \% b_{0} ; \mathrm{P}_{\mathrm{FE}}=$ ultimate strength determined by FEA, $\mathrm{P}_{\text {ult }}=$ ultimate strength by test.

\subsection{Numerical Research Program}

In this section, the behavior of DPR-SHS T-joint is further discussed by numerical parameter study. The geometries of the chord or brace and the finite element strategy were the same as before. However, the material model and the restraint condition were simplified. For example, to eliminate the influence of material nonlinearity, the perfect elastic-plastic material model was used. The yielding strength of the steel for the chord was $345 \mathrm{~N} / \mathrm{mm}^{2}$, and the steel for the brace was determined as $420 \mathrm{~N} / \mathrm{mm}^{2}$ to prevent the unexpected brace buckling as observed in the experiment. In addition, the bottom surface of the chord was continuous supported to eliminate the influence of overall chord bending.

In the parameter study, the effect of the doubler-plate geometry and material on the compression strength of the joint was mainly concerned. At first, three unreinforced T-joints with the brace-to-chord width ratio of $0.4,0.6$ and 0.8 were modeled as benchmark specimens. Then, a large number of DPR joints were simulated by changing the width, the length or the thickness of the doubler-plate. In addition, the yielding strength of doubler-plate was determined as $235 \mathrm{~N} / \mathrm{mm}^{2}$ or $345 \mathrm{~N} / \mathrm{mm}^{2}$ for the joints with the parameter of $\beta_{2}=0.9$. Overall, 3 unreinforced and 120 DPR-SHS T-joints were analyzed, as listed in Table 4.

Table 4. Reinforcement Parameters for FEA

\begin{tabular}{c|c|c|c|c|c|c}
\hline No & $b_{0} \times h_{0} \times t_{0}$ & $b_{1} \times h_{1} \times t_{1}$ & $\beta$ & $\beta_{2}=b_{2} / b_{0}$ & $\tau_{2}=t_{2} / t_{0}$ & $\eta_{2}=h_{2} / b_{0}$ \\
\hline DP40-FE & $100 \times 100 \times 5$ & $40 \times 40 \times 4$ & 0.4 & $0.7 ; 0.8 ; 0.9^{*}$ & $1.0 ; 1.4 ; 2.0$ & $0.8 ; 1.0 ; 1.2 ; 1.6 ; 2.0$ \\
\hline DP60-FE & $100 \times 100 \times 5$ & $60 \times 60 \times 4$ & 0.6 & $0.9^{*}$ & $1.0 ; 1.4 ; 2.0$ & $0.8 ; 1.0 ; 1.2 ; 1.6 ; 2.0$ \\
\hline DP80-FE & $100 \times 100 \times 5$ & $80 \times 80 \times 4$ & 0.8 & $0.9^{*}$ & $1.0 ; 1.4 ; 2.0$ & $0.9 ; 1.0 ; 1.2 ; 1.6 ; 2.0$ \\
\hline
\end{tabular}

Note: ${ }^{*}$ the yielding strength of the doubler-plate was $235 \mathrm{~N} / \mathrm{mm}^{2}$ or $345 \mathrm{~N} / \mathrm{mm}^{2}$. 


\subsection{Load-displacement Curves}

By picking the displacement and the reaction force at the end of the brace, the load-deformation curves of the simulated joints are shown in Figure 9. It can be seen from Figure 9 the curves of DPR-SHS T-joints are far above the unreinforced ones. The compression strength of the joint increased apparently by increasing the thickness of the doubler-plate. Yet the influence of the doubler-plate width or length was not obvious. For example, the curves almost coincide when the length of the doubler-plate exceeded a certain range (namely: $\eta_{2} \geq 1.6$ ), which indicated the strength of the joint tends unchanged. For the DPR-SHS joints with a small width ratio (namely: $\beta \leq 0.6$ ), the load-deformation curves did not have a pronounced peak load, demonstrating the yielding of chord flange (Figure 10a) occurred (Zhao [25]). Conversely, the load-deformation curves for joint of $\beta=0.8$ had obvious peak load, indicating the failure mode of chord web buckling (Figure 10b) occurred (Zhao [25]).
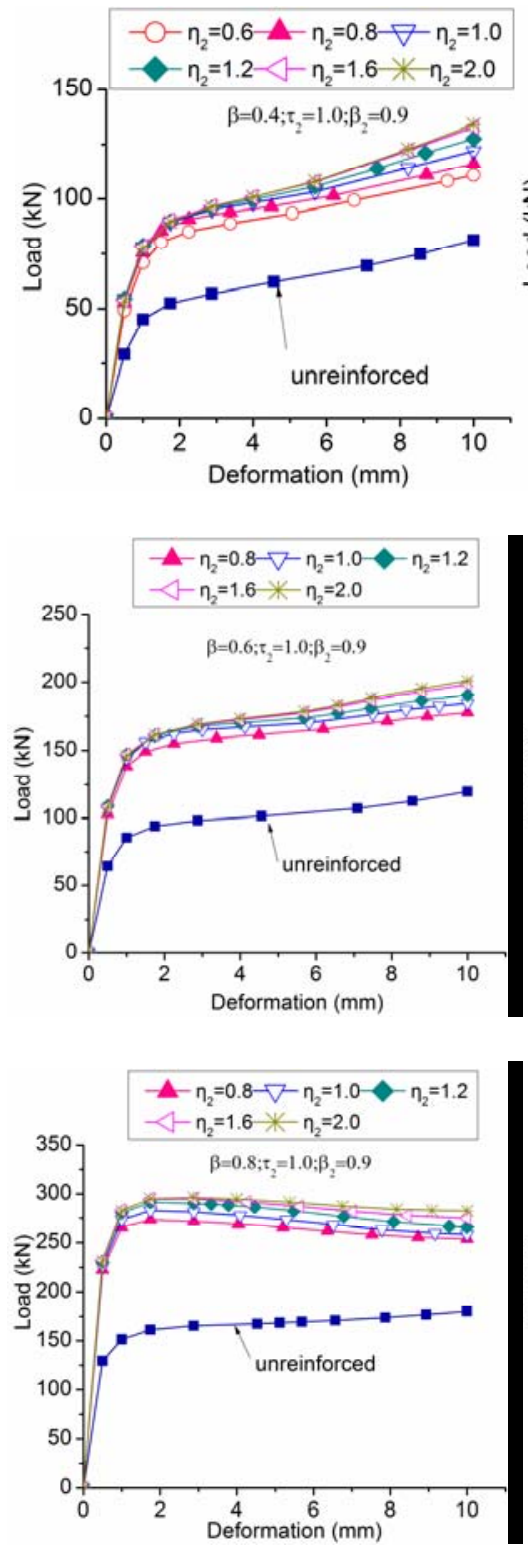

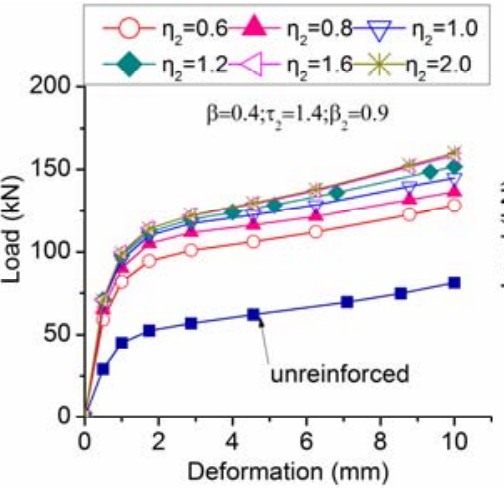

(a) DP40-FE

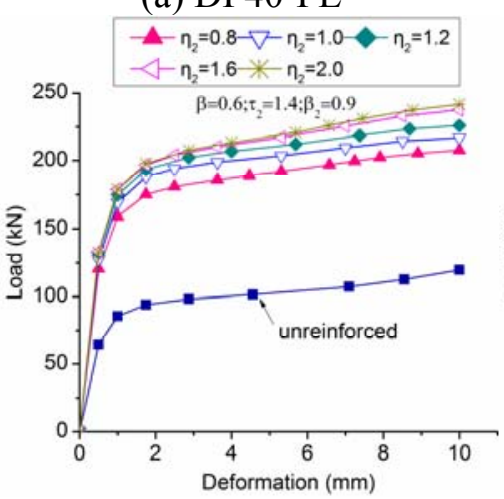

(b) DP60-FE

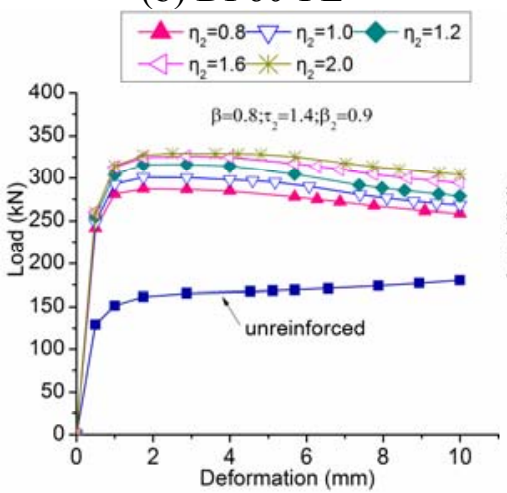

(c) DP80-FE
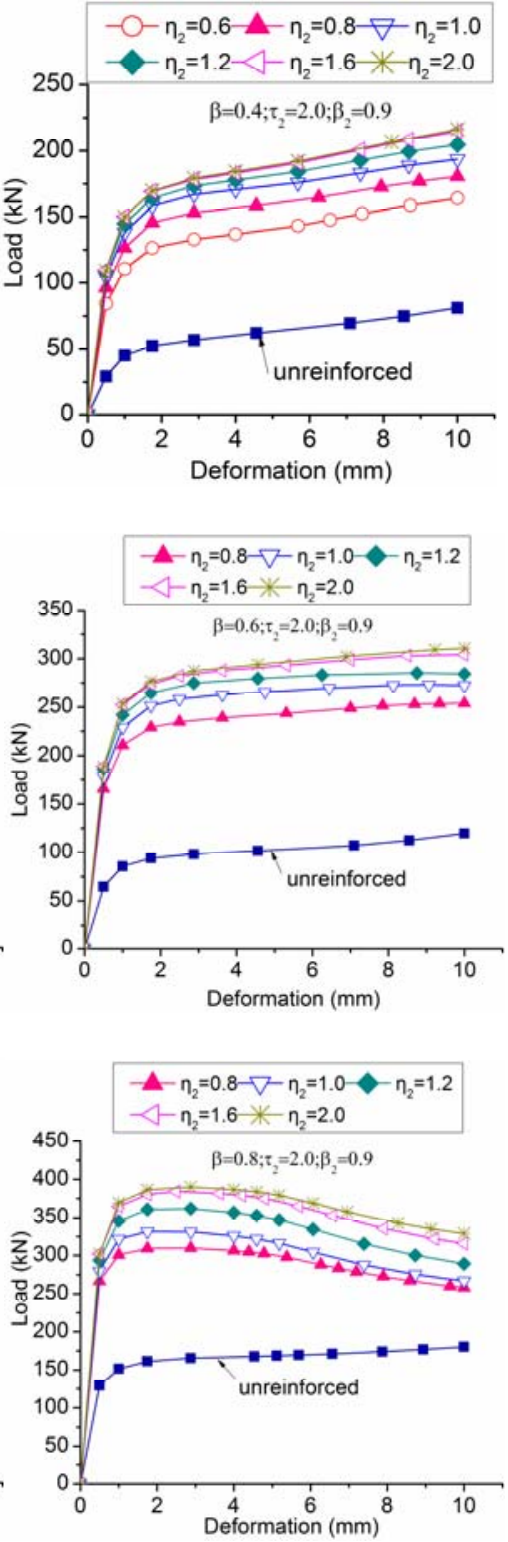

Figure 9. Typical Load-deformation Curves of FE Simulation 


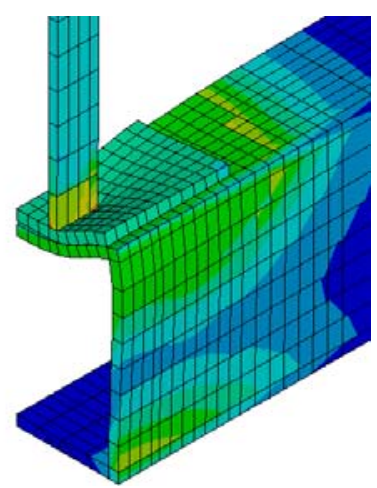

(a) chord flange and doubler-plate yielding Figure 10. Typical Failure Mode of DPR-SHS Joints

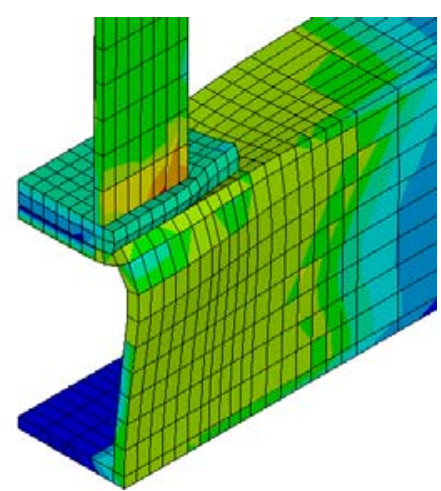

(b) chord web buckling

\subsection{Sensitivity Analysis}

In this section, the influence of doubler-plate geometry or material on the compression strength of DPR T-joint is further analyzed. The compression strength of each simulated specimen is tabulated in Table 5. In the parametric analysis, the reinforcing efficiency of doubler-plate can be investigated by analyzing the effect of one normalized parameter, i.e. $R_{\mathrm{E}}$, representing the ratio of compression strength incremental for DPR-SHS joint and four times plastic moment per unit length of the doubler-plate.

$$
R_{E}=\frac{P_{d p}-P_{y 0}}{f_{y 2} t_{2}^{2}}
$$

In which $P_{d p}$ is the compression strength of the DPR-SHS T-joint, $P_{y 0}$ is the compression strength of the unreinforced T-joint, $f_{y 2}$ is the yielding strength of the doubler-plate, $t_{2}$ is the thickness of the doubler-plate.

Table 5. Compression Strength of the Joints by FEA $(\mathrm{kN})$

\begin{tabular}{|c|c|c|c|c|c|c|c|c|}
\hline \multirow{2}{*}{ NO } & \multirow{2}{*}{$\beta$} & \multirow{2}{*}{$\beta_{2}$} & \multirow[b]{2}{*}{$\tau_{2}$} & \multicolumn{5}{|c|}{$\eta_{2}$} \\
\hline & & & & 0.8 & 1.0 & 1.2 & 1.6 & 2.0 \\
\hline \multirow{13}{*}{ DP40-FE } & \multirow{13}{*}{0.4} & 0 & 0 & \multicolumn{5}{|c|}{57.1} \\
\hline & & 0.7 & 1.0 & 94.3 & 96.9 & 97.5 & 98.1 & 97.9 \\
\hline & & 0.7 & 1.4 & 110.9 & 115.8 & 117.7 & 119.3 & 119.6 \\
\hline & & 0.7 & 2.0 & 137.6 & 146.8 & 149.8 & 153.2 & 154.8 \\
\hline & & 0.8 & 1.0 & 94.5 & 97.3 & 98 & 98.9 & 98.6 \\
\hline & & 0.8 & 1.4 & 112.3 & 118 & 120.3 & 122.3 & 122.6 \\
\hline & & 0.8 & 2.0 & 152.5 & 165.5 & 171.3 & 175.5 & 176.5 \\
\hline & & 0.9 & 1.0 & 92.9 & 95.6 & 96.3 & 97.1 & 96.9 \\
\hline & & 0.9 & 1.4 & 112.1 & 117.7 & 120.3 & 122.6 & 122.9 \\
\hline & & 0.9 & 2.0 & 153.4 & 167.3 & 173.8 & 178.7 & 179.7 \\
\hline & & $0.9^{*}$ & 1.0 & 107.2 & 111.2 & 112.3 & 113.3 & 112.9 \\
\hline & & $0.9^{*}$ & 1.4 & 133 & 142.7 & 147 & 150.5 & 150.8 \\
\hline & & $0.9^{*}$ & 2.0 & 187 & 207.7 & 218.5 & 227 & 228.5 \\
\hline \multirow{3}{*}{ DP60-FE } & \multirow{3}{*}{0.6} & $\beta_{2}$ & & \multicolumn{5}{|c|}{$\eta_{2}$} \\
\hline & & $\beta_{2}$ & $\tau_{2}$ & 0.8 & 1.0 & 1.2 & 1.6 & 2.0 \\
\hline & & 0 & 0 & \multicolumn{5}{|c|}{98.3} \\
\hline
\end{tabular}




\begin{tabular}{|c|c|c|c|c|c|c|c|c|}
\hline & & 0.9 & 1.0 & 157.5 & 165 & 167.8 & 168.8 & 169.5 \\
\hline & & 0.9 & 1.4 & 182.8 & 196 & 202.7 & 206.7 & 208.3 \\
\hline & & 0.9 & 2.0 & 236.6 & 260.2 & 275.3 & 284.8 & 287.9 \\
\hline & & $0.9^{*}$ & 1.0 & 179.8 & 190.8 & 195.2 & 196.6 & 197.1 \\
\hline & & $0.9^{*}$ & 1.4 & 214.3 & 232.8 & 243.5 & 249.7 & 251.6 \\
\hline & & $0.9^{*}$ & 2.0 & 280 & 310.8 & 330.3 & 343.2 & 351.1 \\
\hline \multirow{9}{*}{ DP80-FE } & \multirow{9}{*}{0.8} & \multirow{2}{*}{$\beta_{2}$} & \multirow{2}{*}{$\tau_{2}$} & \multicolumn{5}{|c|}{$\eta_{2}$} \\
\hline & & & & 0.9 & 1.0 & 1.2 & 1.6 & 2.0 \\
\hline & & 0 & 0 & \multicolumn{5}{|c|}{165.6} \\
\hline & & 0.9 & 1.0 & 273.4 & 282.9 & 291.2 & 294.8 & 296 \\
\hline & & 0.9 & 1.4 & 286.4 & 300.4 & 316.1 & 325.9 & 329 \\
\hline & & 0.9 & 2.0 & 309.5 & 330.3 & 361.4 & 383.2 & 389.7 \\
\hline & & $0.9^{*}$ & 1.0 & 301.6 & 314.9 & 326.9 & 333.9 & $\overline{334.6}$ \\
\hline & & $0.9^{*}$ & 1.4 & 315.6 & 336.6 & 357 & 372.5 & 377.1 \\
\hline & & $0.9^{*}$ & 2.0 & 333.1 & 357.6 & 403.6 & 432.6 & 441.7 \\
\hline
\end{tabular}

The influence of doubler-plate geometry and material on the reinforcing efficiency is shown in Figure 11. It can be seen from Figure 11(a) the width of doubler-plate has little influence on the reinforcing efficiency of joint when the thickness of doubler-plate was fewer than $1.4 t_{0}$. However, as the thickness of doubler-plate was $2.0 t_{0}$, the reinforcing efficiency increased with the increase of doubler-plate width. For construction convenience, the width of doubler-plate can be determined equal to the flat width of the chord flange (ie. $b_{0}-4 t_{0}$ ), which was consistent with that proposed by Korol [14] or CIDET [21].

It is common the thicker of the doubler-plate, the stronger of the DPR joint [14]. However, the situation was contrary for reinforcing efficiency, which decreased significantly as the thickness of doubler-plate increased, as shown in Figure 11(b). For example, for the joint with $\beta=0.4, \beta_{2}=0.9$ and $\eta_{2}=1.0$, as $\tau_{2}$ increased from 1.0 to 1.4 and 2.0, the reduction of $R_{\mathrm{E}}$ were $19.7 \%$ and $28.4 \%$, respectively. Similarly, the reduction were $25.3 \%$ and $39.3 \%$ for joint with $\beta=0.6$, and $41.4 \%$ and $64.9 \%$ for joint with $\beta=0.8$. Thus, the use of large thickness doubler-plate was unnecessary, and a thickness ratio for doubler-plate and chord under 2.0 was appreciated.

From Figure 11 (b), it can also be seen the influence of doubler-plate thickness increased as the width ratio increased. For example, for the joint with $\tau_{2}=1.0, \beta_{2}=0.9$ and $\eta_{2}=1.0$, as $\beta$ increased from 0.4 to 0.6 and 0.8 , the increase of $R_{\mathrm{E}}$ were $73.2 \%$ and $204.7 \%$, respectively. However, a width ratio of under 0.8 was more appropriate for the application of doubler-plate reinforcement, for the reason of fabrication convenience.

The reinforcing efficiency increased with the increase of the doubler-plate length, as shown in Figure 11(c). For example, for the joint with $\beta=0.4, \beta_{2}=0.9$ and $\tau_{2}=1.0$, as $\eta_{2}$ increased from 0.8 to $1.0,1.2,1.6$ and 2.0 , the increase of $R_{\mathrm{E}}$ were $7.5 \%, 9.5 \%, 11.7 \%$ and $11.2 \%$, respectively. Similarly, the increase were $12.7 \%, 17.4 \%, 19.1 \%$ and $20.3 \%$ for joint with $\beta=0.6$, and $8.9 \%$, $16.5 \%, 19.9 \%$ and $21 \%$ for joint with $\beta=0.8$. For all the joints analyzed, it was interesting that the increase of $R_{\mathrm{E}}$ trends to be slowdown when $\eta_{2}$ exceed 1.6, demonstrating an optimal range of doubler-plate length existed (Korol [14]).

It can be seen from Table 5 the strength of DPR joint increased with the increase of doubler-plate yielding strength. Nevertheless, the reinforcing efficiency decreased slightly, as shown in Figure 11(d). For example, for the joint with $\beta=0.4, \beta_{2}=0.9, \eta_{2}=1.0$ and $\tau_{2}=1.0$, as $f_{\mathrm{y} 2}$ increased from 235 to 345 , the reduction of $R_{\mathrm{E}}$ were $7.4 \%$. Similarly, the reduction were $5.5 \%$ and $13.3 \%$ for joint with 
$\beta=0.6$ and $\beta=0.8$. Therefore, it was unnecessary to use high strength steel for doubler-plate. The yielding strength of the doubler-plate can be the same as or even less than the chord.

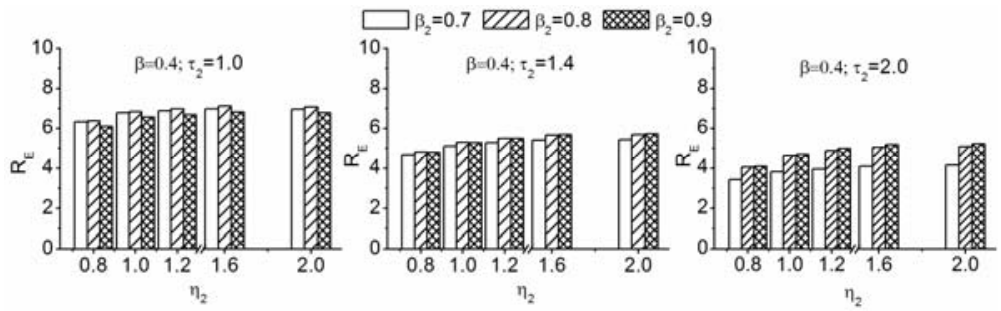

(a) Influence of doubler-plate width on $R_{\mathrm{E}}$

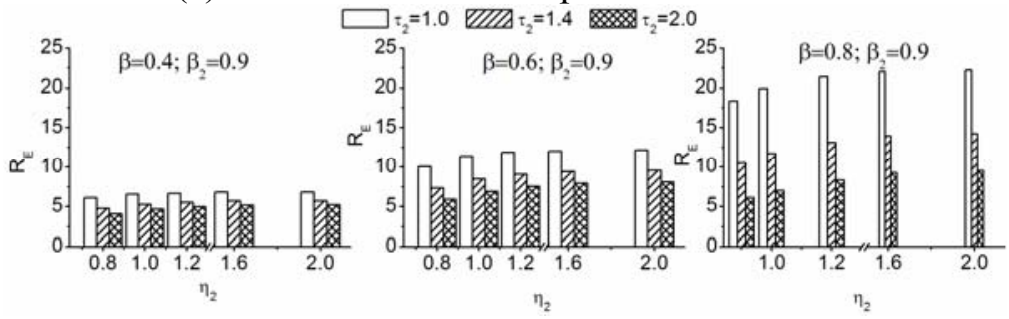

(b) Influence of doubler-plate thickness on $R_{\mathrm{E}}$

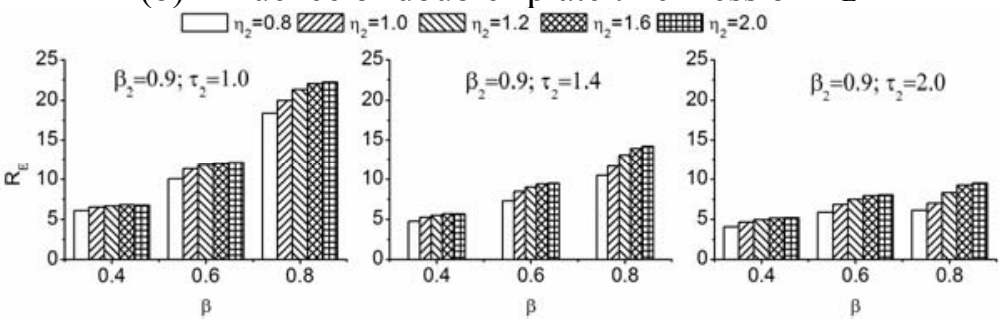

(c) Influence of doubler-plate length on $R_{\mathrm{E}}$
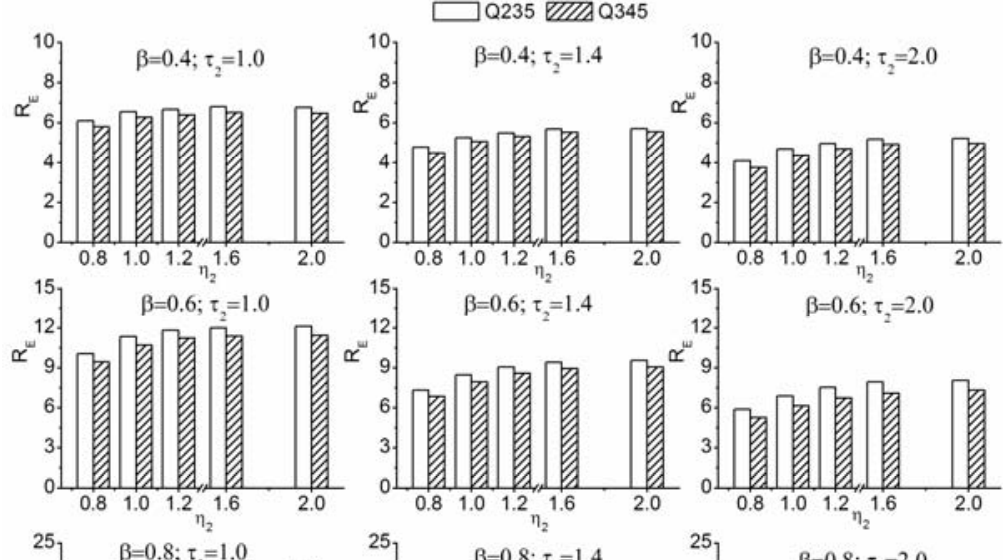

$\begin{aligned} & 15 \\ & 12\end{aligned} \quad \beta=0.6 ; \tau_{2}=2.0$
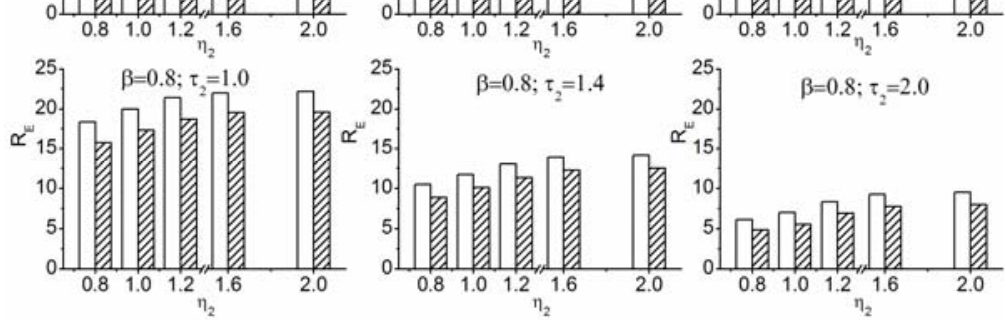

(d) Influence of doubler-plate yielding strength on $R_{\mathrm{E}}$

Figure 11. Influence of Doubler-plate Parameters on the Reinforcing Efficiency of Joint 


\section{ANALYTICAL INVESTIGATION ON COMPRESSION STRENGTH OF DPR-SHS T-JOINTS}

In this section, the reinforcement mechanism of doubler-plate is analyzed. The stress distribution of the unreinforced or reinforced joints is compared firstly, and then the compression strength of the joint is analyzed with yielding line method.

\subsection{Stress Distribution of DPR-SHS Joints}

The equivalent Von Mises stress contours of unreinforced or DPR-SHS T-joints are shown in Figure 12. It can be seen the stress distribution of the chord for DPR-SHS joint consistent well with the unreinforced one. The doubler-plate deformed and yielded together with the chord flange under brace compression load, had very little influence on the stress distribution of the chord. Further more, when the displacement of the brace was equal to $3 \% b_{0}$, the stress distribution along the centerline or edge-line of the chord flange was picked and pictured in Figure 13. The stress distribution of the chord flange for DPR-SHS joints was almost the same as unreinforced ones, and the length of yielding zone on chord flange remained unchanged with the increase of $\eta_{2}$.

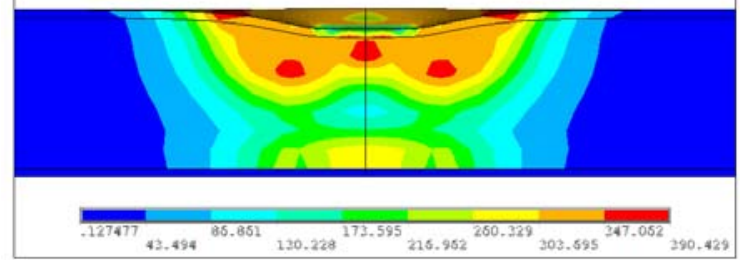

(a) unreinforced joint,

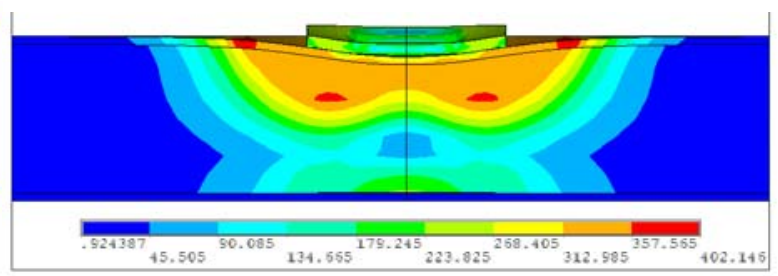

(b) DP60-FE $\left(\tau_{2}=1.4 ; \beta_{2}=0.9 ; \eta_{2}=1.2\right)$

Figure 12. Comparison of Equivalent Stress Contours
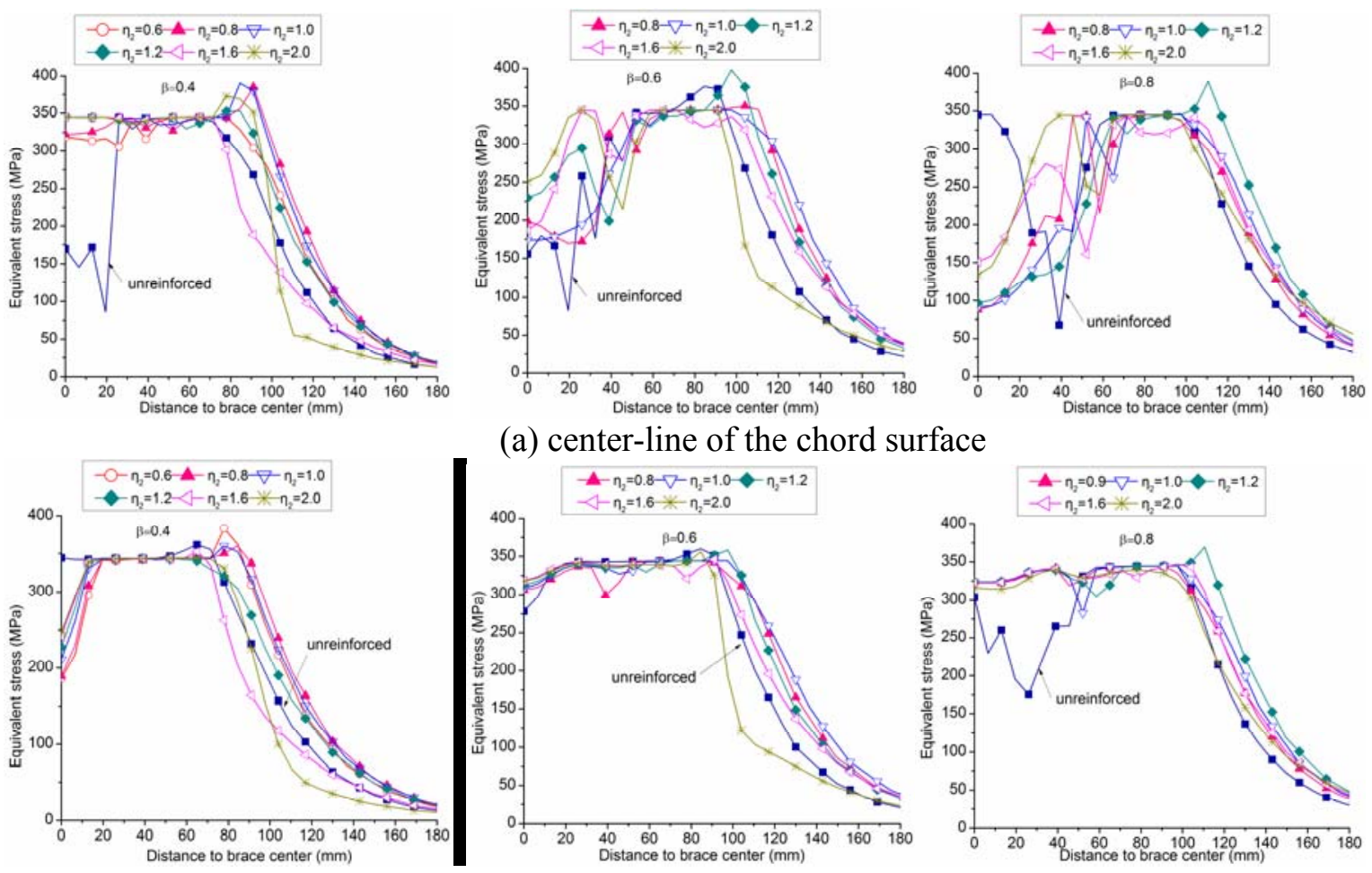

(a) center-line of the chord surface
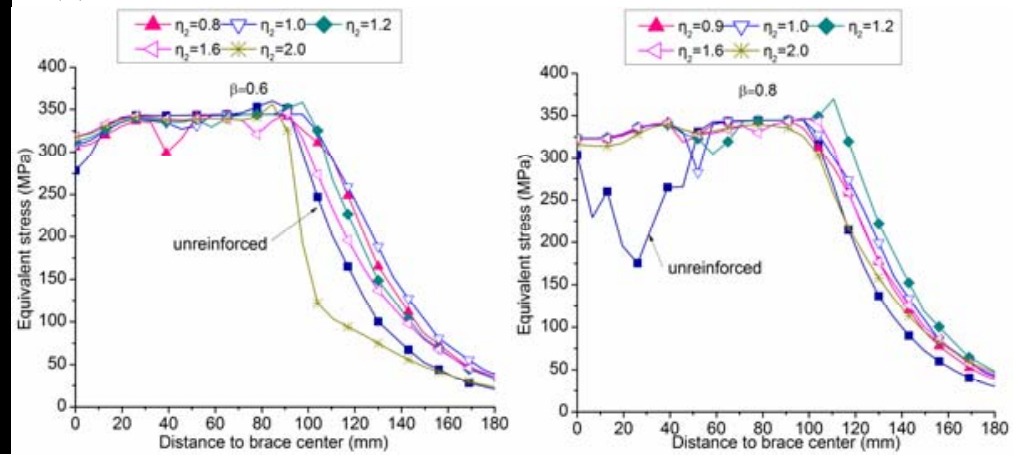

(b) edge-line of the chord surface

Figure 13. Equivalent Stress Distribution of the Chord Surface 


\subsection{Yielding Line Analysis}

Both the experimental tests and finite element simulations indicated the doubler-plate improves the compression strength of the joint obviously, yet does not change the behaviors (namely: failure mode, stress distribution or yielding zone) of the joint. Therefore, the yielding line theory is adopted to estimate the compression strength of the DPR-SHS T-joint in this section. For an unreinforced SHS T-joint under brace compression, a set of yielding lines may develop on the chord flange when the failure of surface yielding controlled, as shown in Figure 14(a). The strength of the joint is (EC3 [20]):

$$
P_{y 0}=\frac{2 f_{y 0} t_{0}^{2}}{1-\beta}\left(\frac{h_{1}}{b_{0}}+2 \sqrt{1-\beta}\right)
$$

In which $f_{y 0}$ is the yielding strength of the chord, $\beta=b_{0} / b_{1}$ is the width ratio of the brace and the chord. The rest of the symbols are the same as shown in Figure 1.

As discussed before, the doubler-plate improved the compression strength of the joint by deforming and yielding together with the surface of the chord. However, the yielding lines on the doubler-plate may different, when the length of the doubler-plate increased (Korol [14]) progressively as shown in Figure 14 (b)-(d). By assuming the yielding pattern of the chord flange unchanged by the doubler-plate, the yielding lines on the doubler-plate can be drawn as the thick solid lines in Figure 14 (b)-(d). Table 6 lists the length and quantity of each yielding line of the DPR-SHS joint. Then the nominal compression strength of the DPR-SHS T-joint can be expressed as:

$$
\begin{aligned}
& P_{y-d p 1}=P_{y 0}+\frac{f_{y 2} t_{2}^{2}}{\left(b_{0}-b_{1}\right)}\left[h_{1}+h_{2}+\left(b_{1}+b_{2}\right) \sqrt{1-\beta}+\left(h_{2}-h_{1}\right)(2-\beta)\right] \\
& P_{y-d p 2}=P_{y 0}+\frac{f_{y 2} t_{2}^{2}}{\left(b_{0}-b_{1}\right)}\left[h_{1}+h_{2}+\left(b_{2}+b_{1}\right) \sqrt{1-\beta}+\frac{\left(b_{2}-b_{1}\right)(2-\beta)}{\sqrt{1-\beta}}\right] \\
& P_{y-d p 3}=P_{y 0}+\frac{f_{y 2} t_{2}^{2}}{\left(b_{0}-b_{1}\right)}\left[2 h_{1}+\left(b_{0}-b_{1}\right) / \sqrt{1-\beta}+\left(b_{2}+b_{1}\right) \sqrt{1-\beta}+\left(b_{2}-b_{1}\right)(2-\beta) / \sqrt{1-\beta}\right]
\end{aligned}
$$

In which $P_{y 0}$ is the strength of unreinforced joint, $P_{y-d p 1}, P_{y-d p 2}$ and $P_{y-d p 3}$ is the ultimate compression strength corresponds to the situation of $\mathrm{b}, \mathrm{c}$ and $\mathrm{d}$ in Figure 14 respectively, $f_{y_{2}}$ is the yielding strength of the doubler-plate. The rest of the symbols are the same as shown in Figure 1.

Note Eq. 3 - Eq. 5 were based on the assumption of chord surface yielding failure mode controlled. However, the chord web buckling or brace buckling may occur when the chord flange was "over-reinforced" by doubler-plate, as has been proved in the laboratory test (Figure 3) and FE simulation (Figure 8). Therefore, the ultimate compression strength of DPR-SHS joints should be checked by the failure strength of chord web buckling and brace buckling. 


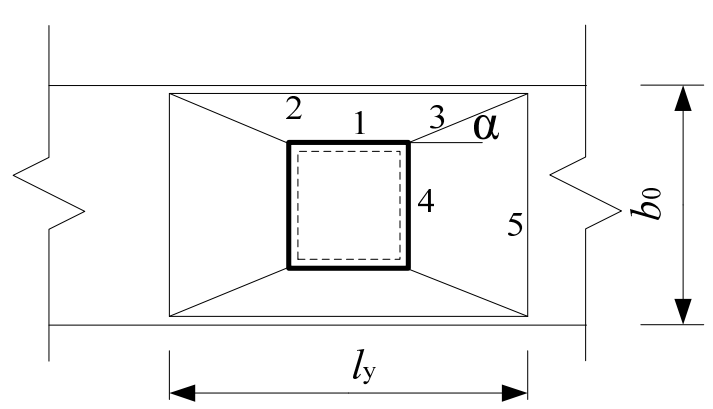

(a) unreinforced joint

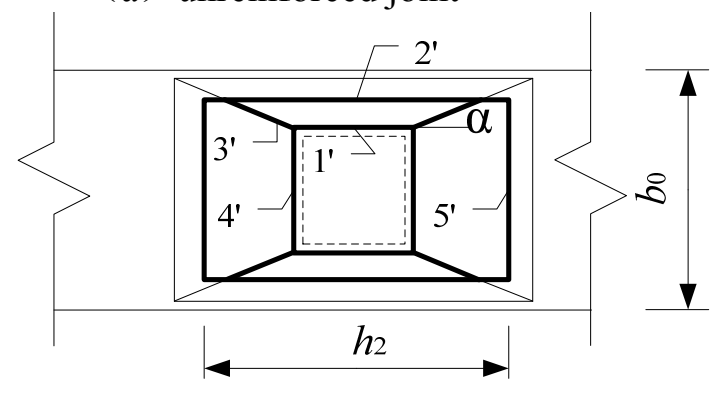

(c) DPR-SHS joint: case-2

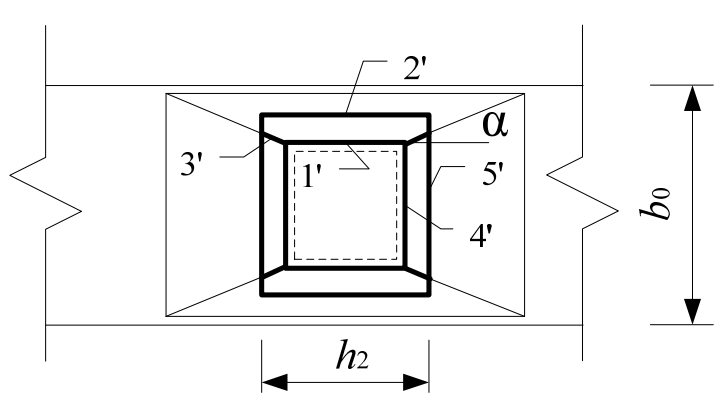

(b) DPR-SHS joint: case-1

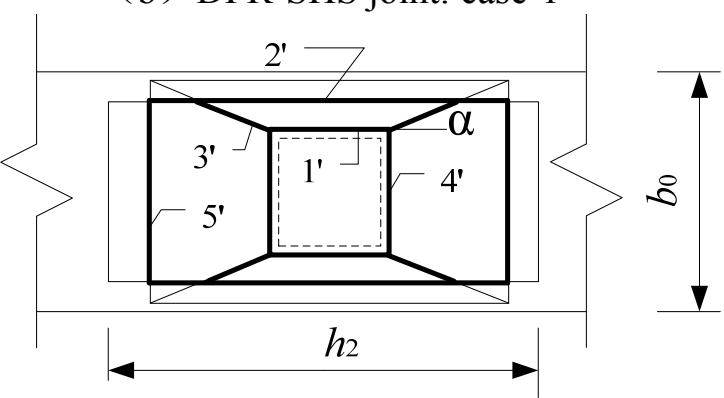

(d) DPR-SHS joint: case-3

Figure 14. Yielding Lines of the Chord Surface or Doubler-plate

Table 6. Length and Quantity of Yielding Lines on Doubler plate

\begin{tabular}{c|c|c|c|c}
\hline No & quantity & $\begin{array}{c}\text { Case- } 1 \\
h_{2} \leq h_{1}+\left(b_{2}-b_{1}\right) \cot \alpha\end{array}$ & $\begin{array}{c}\text { Case-2 } \\
h_{1}+\left(b_{2}-b_{1}\right) \cot \alpha \leq h_{2} \\
\leq h_{1}+\left(b_{0}-b_{1}\right) \cot \alpha\end{array}$ & $\begin{array}{c}\text { Case-3 } \\
h_{1}+\left(b_{0}-b_{1}\right) \cot \alpha \leq h_{2}\end{array}$ \\
\hline $1^{\prime}$ & 2 & $h_{1}$ & $h_{1}$ & $h_{1}$ \\
\hline $2^{\prime}$ & 2 & $h_{2}$ & $h_{2}$ & $h_{1}+\left(b_{0}-b_{1}\right) \cot \alpha$ \\
\hline $3^{\prime}$ & 4 & $\frac{\left(h_{2}-h_{1}\right)}{2 \cos \alpha}$ & $\frac{\left(b_{2}-b_{1}\right)}{2 \sin \alpha}$ & $\frac{\left(b_{2}-b_{1}\right)}{2 \sin \alpha}$ \\
\hline $4^{\prime}$ & 2 & $b_{1}$ & $b_{1}$ & $b_{1}$ \\
\hline 5 & 2 & $b_{2}$ & $b_{2}$ & $b_{2}$ \\
\hline
\end{tabular}

To check the accuracy of the proposed formulas, the FEA compression strength of the DPR-SHS T-joints, as well as the formula predicted values are plotted in Figure 15. Meanwhile, the strength calculated by Korol [14], Soh [16] and EC3 [20] are plotted for comparison.

The formulas of Korol [14] were proposed by theoretical derivation, and no verification tests were conducted for DPR-SHS T-joint under brace compression, which seems to have overestimated the compression strength of DPR-SHS T-joint. Soh [16] analyzed the compression strength of doubler-plate reinforced T-joint by experimental test and finite element parametric study, and proposed the strength formula by regression analysis. However, the influence of doubler-plate geometry was not included by Soh [16], which leading to an underestimation of the strength for DPR-SHS T-joint. In contrast, the accuracy of EC3 [20] and Eq. 3 - Eq. 5 was more satisfactory. 


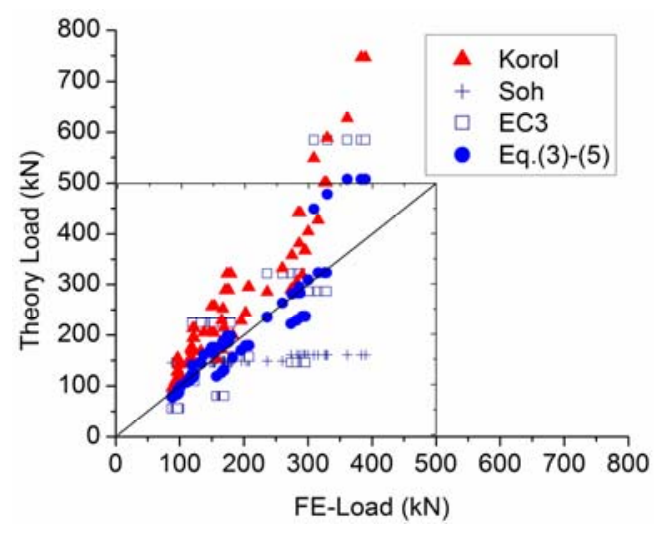

Figure 15. Comparison of Theory and FEA Determined Compression Strength

Furthermore, a detailed comparison between EC3 and Eq. 3 - Eq. 5 is demonstrated in Figure 16. The vertical axes $\mathrm{P}_{\mathrm{TH}} / \mathrm{P}_{\mathrm{FE}}$ indicates the ratio of compression strength determined by formulas (EC3 or Eq.3-5) and FEA, the closer of $\mathrm{P}_{\mathrm{TH}} / \mathrm{P}_{\mathrm{FE}}$ to 1.0, the more accurate of the formula. Note EC3 [20] determines the compression strength of DPR-SHS joints by replacing $t_{0}$ with $t_{2}$ in Eq. 2, neglects the influence of the doubler-plate parameters variety. The ratio of $\mathrm{P}_{\mathrm{TH}} / \mathrm{P}_{\mathrm{FE}}$ for EC3 is relatively discrete. When the thickness of the doubler-plate is small (namely: $\tau_{2}=1.0$ ), the code of EC3 [20] underestimates the compression strength of DPR-SHS joint about 40\%-50\%. However, an overestimate of $20 \%-80 \%$ by EC3 [20] is demonstrated for the joint with thick doubler-plate (namely: $\tau_{2}=2.0$ ) or high width ratio (namely: $\beta=0.8$ ). Overall, the mean ratio of $\mathrm{P}_{\mathrm{TH}} / \mathrm{P}_{\mathrm{FE}}$ for EC3 [20] is 0.97 with a COV of 0.15 .

The accuracy of Eq. 3- Eq. 5 is more satisfactory, with a mean $\mathrm{P}_{\mathrm{TH}} / \mathrm{P}_{\mathrm{FE}}$ ratio of 0.99 and a COV of 0.02. Most of the $\mathrm{P}_{\mathrm{TH}} / \mathrm{P}_{\mathrm{FE}}$ ratios range from 0.8 to 1.2 , demonstrating a very good convergence. However, the compression strength of the joint may be overestimated when the width ratio of the joint is 0.8 . This mainly due to the failure of chord web buckling (Figure 10b) occurred, which prevent the full development of doubler-plate yielding.

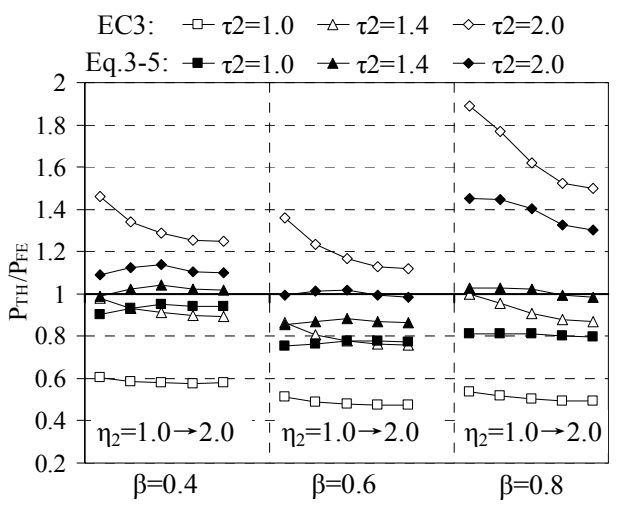

Figure 16. Comparison of EC3 and Eq. 3-5 


\section{CONCLUSIONS AND RECOMMENDATIONS}

Effects of doubler-plate reinforcement on the compression behavior of square tubular T-joint were studied by laboratory tests and finite element analysis. The influence of doubler-plate geometry and material was discussed, and the mechanism of doubler-plate reinforcement was investigated. Finally, an analytical method was proposed to predict the nominal compression strength of DPR-SHS T-joints. Given the results presented in this study, the following conclusions can be drawn:

(1) Welding a doubler-plate on the surface of the chord provides a significant improvement in the compression strength of the SHS joint, yet does not change the stress distribution of the chord flange. Given a proper geometry, the reinforcement mechanism of doubler-plate is yielding together with the chord flange.

(2) The strength of a DPR-SHS joint can be significant improved by increasing the doubler-plate thickness, while insignificant by increasing the width or length of doubler-plate. However, it should be emphasized the failure of web or brace buckling may occur if the thickness exceeds a certain range.

(3) The reinforcement efficiency of the doubler-plate increased with the increase of doubler-plate width $\left(\beta_{2}\right)$ and length $\left(\eta_{2}\right)$, yet decreased with the increase of doubler-plate thickness $\left(\tau_{2}\right)$ and yielding strength $\left(f_{\mathrm{y} 2}\right)$.

(4) Yielding line method is still valid to develop a theoretical model for the nominal compression strength of DPR-SHS joints, and the theoretical results agree well with the experimental and FE findings. While for design purpose, the theoretical strength should always be checked for possible web buckling or member failure.

For the application of doubler-plate reinforcement under brace compression, a width ratio of $\beta<0.8$ is appropriate, to avoid the problem of "over-reinforcement" as well as "fabricate difficulty". Based on the above analysis, the width, length and thickness of the doubler-plate can be determined as: $\beta_{2}=1-4 t_{0} / b_{0}, 1.5 \leq \eta_{2} \leq 2.0,1.0 \leq \tau_{2}<2.0$. The yielding strength of doubler-plate can be determined according to the strength requirement of the joint, a high strength doubler-plate was unnecessary.

For the design of DPR-SHS joints, the EC3 [20] seems to have over-simplified the compression strength estimation of DPR-SHS joints. By considering the co-yielding of the doubler-plate and the chord flange, as well as the influence of the doubler-plate parameters variety, the compression strength of DPR-SHS joints was more accurately estimated. However, the recommended formulas should be confirmed with more test or FEM evidences, and the simplification of the formulas is also needed, both of which will complete in the next stage.

\section{ACKNOWLEDGMENTS}

Thanks to the financial support of the National Science Foundation (51274192), the Jiangsu Civil Engineering Graduate Center for Innovation and Academic Communication foundation, the Jiangsu Province Science Foundation (BK20140195), the priority academic program development of Jiangsu higher education institutions and the Fundamental Research Funds for the Central Universities (2011QNB17). 


\section{REFERENCES}

[1] Wardenier J., "Hollow Sections in Structural Application", Delft: Delft University Press; 2001.

[2] Lesani, M., Bahaari, M.R. and Shokrieh, M.M., "Detail Investigation on Un-stiffened T/Y Tubular Joints Behavior under Axial Compressive Loads”, J. Const. Steel Res. 2013, Vol. 80, pp. 91-9.

[3] Packer, J.A. and Henderson, J.E., "Hollow Structural Section Connections and Trusses-A Design Guide, $3^{\text {rd }}$ ed.", Toronto: Canadian Institute of Steel Construction; 1997.

[4] Shao, Y.B., Li, T., Lie, S.T. and Chiew, S.P., "Hysteretic Behaviour of Square Tubular T-joints with Chord Reinforcement under Axial Cyclic Loading”, J. Constr. Steel Res. 2011, Vol. 67, No. 1, pp. 140-9.

[5] Nazari, A., Guan, Z., Daniel, W.J.T. and Gurgenci, H., "Parametric Study of Hot Spot Stresses Around Tubular Joints with Doubler Plates", Pract. Period Struct. Des. Constr. 2007, Vol. 12, No. 1, pp. 38-47.

[6] Soh, C.K., Chan, T.K., Fung, T.C. and Nakacho, K., "Stress Concentration Factors of Reinforced Square Hollow Section T-joints", Trans. JWRI 2001, Vol. 30, No. 2, pp. 103-08.

[7] Lee, M.M.K. and Llewelyn-Parry, A., "Offshore Tubular T-joints Reinforced with Internal Plain Annular Ring Stiffeners”, J. Struct. Eng., 2004, Vol. 130, No. 6, pp. 942-51.

[8] Hoon, K.H., Wong, L.K. and Soh, A.K., "Experimental Investigation of a Doubler-plate Reinforced Tubular T-joint Subjected to Combined Loadings", J. Constr. Steel Res. 2001, Vol. 57, No. 9, pp. 1015-39.

[9] Choo, Y.S., Vegte, G.J., Zettlemoyer, N. and Li, B.H., "Static Strength of T-Joints Reinforced with Doubler or Collar Plates. I: Experimental Investigations”, J. Struct. Eng. 2005, Vol. 131, No. 1, pp. 119-28.

[10] van der Vegte, G.J., Choo, Y.S., Liang, J.X., Zettlemoyer, N. and Liew, J.Y.R., "Static Strength of T-Joints Reinforced with Doubler or Collar Plates. II: Numerical Simulations", J. Struct. Eng., 2005, Vol. 131, No. 1, pp. 129-38.

[11] Fung, T.C., Chan, T.K. and Soh, C.K., "Ultimate Capacity of Doubler-plate Reinforced Tubular Joints", J. Struct. Eng. 1999, Vol. 125, No. 8, pp. 891-9.

[12] Choo, Y.S., Liang, J.X., Van Der Vegte, G.J. and et al., "Static Strength of Doubler Plate Reinforced CHS X-joints Loaded by In-plane Bending”, J. Const. Steel Res. 2004, Vol. 60, No. 12, pp. 1725-44.

[13] Feng, Q. and Tan, J.H., "The Ultimate Strength of Doubler Plate Reinforced Y-joints under Compression Loading”, J. Mar Sci. Appl., 2005, Vol. 4, No. 2, pp. 13-19.

[14] Korol, R.M., El-Zanaty, M. and Brady, F.J., "Unequal Width Connections of Square Hollow Sections in Vierendeel Trusses", Can J. Civ. Eng., 1977, Vol. 4, No. 2, pp. 190-201.

[15] Korol, R.M., Mitri, H. and Mirza, F.A., "Plate Reinforced Square Hollow Section T-joints of Unequal Width", Can J. Civ. Eng., 1982, Vol. 9, No. 2, pp. 143-8.

[16] Soh, C.K., Chan, T.K., Fung, T.C. and Nakacho, K., "Ultimate Capacity of Doubler Plate Reinforced Square Hollow Section T-joints”, Trans JWRI 2000, Vol. 29, No. 2, pp. 85-90.

[17] Yang, J., Shao, Y.B. and Chen, C., "Static Strength of Chord Reinforced Tubular Y-joints under Axial Loading", Mar Struct. 2012, Vol. 29, pp. 226-45.

[18] Lesani, M., Bahaari, M.R. and Shokrieh, M.M., "Numerical Investigation of FRP-strengthened Tubular T-joints under Axial Compressive Loads", Comp. Struct. 2013, Vol. 100, pp. 71-8.

[19] Jose, A. and Amir, F., "Retrofitting Tubular Steel T-joints Subjected to Axial Compression in Chord and Brace Members using Bonded FRP Plates or Through-wall Steel Bolts", Eng. Struct., 2013, Vol. 48, pp. 602-10. 
[20] European Committee for Standardisation: 2003 European Standard, Design of Steel Structures: Design of Joints.

[21] CIDET: 2009 Design Guide For Rectangular Hollow Section (RHS) Joints Under Predominantly Static Loading.

[22] Wu, Z.Y., Chen, P. and Wang, Y.Y., "Experimental Study on the Hysteretic Behavior of T-type SHS Joints", Chin Civ. Eng. J., 2008, Vol. 41, No. 12, pp. 8-13. (in Chinese)

[23] Chang, H.F., Xia, J.W. and Zhang, F.J., "The Static Performance of Axially Loaded, Square Tubular T-joints", J CUMT 2012, Vol. 41, No. 6, pp. 917-22 (in Chinese)

[24] Lu, L.H., Winkel, G.D., Yu, Y. and Wardenier, J., "Deformation Limit for the Ultimate Strength of Hollow Section Joints" In: Paul Grundy, Alan Holgate editors. Tubular Structures VI. London: Taylor \& Francis Group, 1994, pp. 341-7.

[25] Zhao, X.L., "Deformation Limit and Ultimate Strength of Welded T-joints in Cold-formed RHS Sections”, J. Constr. Steel Res. 2000, Vol. 53, No. 2, pp. 149-65. 